Revista Herencia Vol. 27 (1 y 2), 77-110, 2014

Recibido 30-10-2013 Aprobado 20-11-2013

\title{
Aquella inexplorada región de San Carlos
}

\begin{abstract}
Resumen
Debido a su valor histórico, geográfico, biológico y agronómico, se transcribe aquí el documento Informe sobre el viaje al río San Carlos, publicado en el diario oficial La Gaceta en mayo de 1892. Fue escrito por el experto salvadoreño David J. Guzmán, contratado por el gobierno de Costa Rica como el coordinador nacional para la Exposición Universal de Chicago, realizada en 1893. Además de interpretar varios aspectos de su contenido mediante notas, el documento se complementa con información acerca de los primeros exploradores que recorrieron o estudiaron la región de San Carlos, en Alajuela, Costa Rica.
\end{abstract}

Palabras claves: David J. Guzmán, Geografía, Botánica, Zoología, San Carlos, Costa Rica.

\begin{abstract}
Because of its historical, geographical, biological and agronomic value, the document Report of a trip to the San Carlos River is transcribed here; it was published in La Gaceta, the official Costa Rican newspaper, in May, 1892. It was written by David J. Guzmán, a Salvadorean expert hired by the Costa Rican government as the national coordinator for the World's Columbian Exposition, which took place in Chicago in 1893. In addition to interpreting several aspects of its contents through notes, such document is complemented with information about the first explorers who either visited or studied the San Carlos region, in Alajuela, Costa Rica.
\end{abstract}

Keywords: David J. Guzmán, Geography, Botany, Zoology, San Carlos, Costa Rica.

\section{Introducción}

Hacia el norte y el noreste de Costa Rica, separada del Valle Central por la alta Cordillera Volcánica Central y limitada por el río San Juan y una porción terrestre de la frontera con Nicaragua, se extiende una vasta y feraz región de planicies

Luko Hilje

Quirós. Profesor Emérito. Centro Agronómico Tropical de Investigación y Enseñanza (CATIE). Turrialba, Costa Rica. luko@ice.co.cr - llanuras, caracterizada por su muy alta pluviosidad. Allí están representadas las zonas ecológicas de bosque húmedo tropical, bosque muy húmedo tropical y bosque muy húmedo de premontano, según el sistema de clasificación de zonas de vida de Holdridge (Tosi, 1969); predomina la segunda de estas zonas, típica de altitudes bajas, muy cálidas y lluviosas. 
Todavía a mediados del siglo XIX era una región ignota y casi mítica, excepto para sus pobladores, los indios botos, ancestros de los guatusos o malekus que hoy habitan la zona norte de Costa Rica. Una evidencia de esto se capta en la publicación La ribera derecha del río San Juan, hasta ahora una parte casi completamente desconocida de Costa Rica, del médico y naturalista alemán Alexander von Frantzius, la cual data de 1862; de hecho, él denominaba terra incognita a esa macro-región ocupada hoy por los actuales cantones de Upala, San Carlos y Sarapiquí.

Eso sí, a diferencia de Sarapiquí, cuyo caudaloso río homónimo permitía desde mediados del decenio de 1830 una conexión comercial con el puerto caribeño de San Juan del Norte —en Nicaragua - gracias al río San Juan, la región de San Carlos permanecía ignorada.

\section{Incursiones en la terra incognita}

En el valioso recuento histórico que nos legara von Frantzius (1862), se indica que fue el ramonense Francisco Martínez quien en 1850, junto con una pequeña comitiva, financiada por el español Ramón Toledo, descubrió el río San Carlos e incluso lo pudo navegar hasta su desembocadura en el río San Juan.

Enterado de este hallazgo, ese mismo año, José Victoriano de las Mercedes Fernández Carrillo recorrió la zona y se estableció allí como único colono por largo tiempo; oriundo de la capital, para entonces tenía unos 25 años'. También en 1850, sus opiniones favorables acerca de la zona fueron el estímulo para que se constituyera una compañía de accionistas orientada a construir un camino, aunque esta iniciativa abortaría. No fue sino en 1853 que el gobierno envió una comisión para evaluar la posibilidad de abrir el anhelado camino, tras lo cual dos miembros de la comitiva exploratoria, cuyos nombres no cita von Frantzius, decidieron establecerse allí.

No obstante, menciona una importante iniciativa como lo fue la contratación del barón Alexander von Bülow, por parte de otra compañía de accionistas, para efectuar un estudio exploratorio acerca del camino existente, así como del río San Carlos. Von Frantzius resalta que su paisano presentó el respectivo informe, el cual fue publicado, y que además elaboró un mapa². Sin embargo:

... la compañía, cuyo capital era exiguo, no trabajó sino despacio en el camino y el Gobierno no hizo nada más por él hasta el momento en que, por consejo de von Bülow, colocó un resguardo en la boca del San Carlos, resguardo que se abandonó después de pocos meses. Así perdió siempre más importancia el tráfico por este camino y las colonias no se aumentaron sino con una que se estableció en 1855 y tuvo por principal objeto el cultivo del cacao.

Cabe hacer una digresión aquí para indicar que von Bülow, de origen noble, tras enviudar, se había casado en segundas nupcias con María Theresa Picole. Militar de carrera y con estudios en ingeniería y economía, era un prominente miembro de la Sociedad Berlinesa de Colonización para Centro América, un ente público-privado creado en Prusia con el fin de establecer una colonia agrícola y comercial alemana en algún país centroamericano. Después de fracasar en Santo Tomás de Castilla, Guatemala, hubo un segundo intento en Bluefields, Nicaragua, también fallido, por lo que se instalaron en Angostura, Turrialba entre 1852 y 1853. Una nueva frustración condujo al abandono del proyecto por parte de von Bülow. 
Debido a su notable capacidad profesional, el presidente Juan Rafael Mora Porras lo nombró Superintendente General de Caminos en agosto de 1854, a raíz de lo cual tuvo a su cargo el mantenimiento del estratégico Camino Nacional, que conectaba San José con Puntarenas. Asimismo, al sobrevenir en 1856 la guerra contra el ejército filibustero comandado por el esclavista William Walker, participó en el Estado Mayor de nuestro ejército, pero al regresar a Costa Rica, tras la batalla de Rivas, murió de disentería en Liberia, Guanacaste.

Para retornar al informe de von Bülow, desde el inicio él califica la región de San Carlos como "una parte muy interesante, se puede decir la más importante de toda la República, tanto por su valor político, cuanto por la belleza de sus terrenos y la hermosura de toda su naturaleza" (von Bülow, 1864) , para a continuación argumentar que una ruta por el río San Carlos sería preferible a la existente por el río Sarapiquí, sobre todo por la aptitud de los terrenos aledaños para la agricultura, "donde existen ya algunas partes bien cultivadas" (ibíd.); aunque no menciona los tipos de cultivos. Eso sí, destaca que "el comercio con varios productos del país, como arroz, frijoles, dulce, etc., se extendería mucho, siendo estos frutos muy apreciados y bien pagados en todo el San Juan". (ibíd.).

En cuanto a la naturaleza como tal, von Bülow anota que:

... admirable es la abundancia de excelentes maderas y de su hermosísima vegetación: toda la montaña se encuentra llena de venados y toda especie de cacería, y acercándose al río, por todas partes se ven las huellas de las dantas, lagartos, tigres y otros animales [para concluir indicando que] la temperatura es favorable aunque diversa según la altura³ .

En relación con el informe propiamente dicho, von Bülow anota que la distancia entre San José y Muelle era de unas 20 leguas, y poco más de 15 leguas entre Alajuela y Muelle 4 . Él hace una prolija descripción de la topografía y los cursos de los ríos en todo el trayecto entre Alajuela y Muelle, así como de los pocos asentamientos humanos a lo largo del camino existente, todo lo cual aparece también en su detallado mapa.

Por cierto, en dicho mapa consigna la presencia de la hacienda de Ludwig von Chamier von Schwieder, en las cercanías de la intersección del camino con el río Tacares; este paisano suyo, que era cuñado de Franz Rohrmoser Harder, patriarca de dicha familia en el país — reconocida después por sus notables actividades cafetaleras-, desarrolló obras de ingeniería de gran importancia, además de laborar como agrimensor. Asimismo, anota que en las cercanías de Grecia había una máquina de aserrar, la cual estaba a la vera del río Poró, pues por entonces los pocos aserraderos que había en el país eran hidráulicos, por lo que dependían del flujo continuo de agua para funcionar.

En cuanto a la ruta existente, señala que:

... el camino que sale de Alajuela a Grecia se encuentra todo cultivado de potreros, cañales, milpas, etc., lo mismo que se encuentran en dicho camino más de doscientas casas y algunos trapiches; estando de traficarse por carretas hasta la Barranca. (ibíd.).

Es posible que esta última localidad no fuera un caserío, sino simplemente el punto en el cual la vía cruzaba el río Barranca - el cual se observa en su mapa-, en el actual cantón de Naranjo; quizás no corresponde al actual poblado de Barranca, sino a un punto intermedio entre Llano Bonito y Palmita.

Por cierto, más adelante anota una localidad denominada Tepescuinte [Tepezcuintle], hoy inexistente, pero que está en el punto donde la senda cruzaba el 
río homónimo, ubicado a unos $27 \mathrm{~km}$ de Barranca y $17 \mathrm{~km}$ de Muelle; puesto que en el mapa se localiza entre los ríos Ronrón y Peje, esto sugiere que estaba cerca del actual poblado de Sucre.

A partir de Tepescuinte, von Bülow ya menciona, en primer lugar, los ríos Peje y Platanar, y después el San Rafael, que desemboca en San Carlos, "y en esta confluencia está el situado el muelle que se llama 'Martínez' o 'San Rafael'". Sobre este punto geográfico, acota que "el embarcadero está bien elegido para los botes, pero es preciso construir las casas un poco más al interior, porque en la misma punta entre el San Rafael y San Carlos no hay lugar". De manera complementaria, en su mapa, dicho atracadero se consigna como "El Muelle de Martínez" y poco antes aparece "El Muelle Victoriano". Además, con grandes letras indica que ahí están los terrenos de Victoriano Fernández, los cuales corresponden a 365 caballerías que lindan, por el norte con el río Cooper, por el oeste con el San Carlos y, por el sur con el Peje ${ }^{5}$. Cabe suponer que la primera denominación del muelle alude al pionero Francisco Martínez.

La lectura del informe de von Bülow revela que ya existía un camino rústico por el que podían transitar mulas y el motivo de su inspección era efectuar un reconocimiento de campo para valorar la posibilidad de construir un camino para carretas desde Alajuela hasta Muelle; no obstante, él mismo indica que de San José a Barranca - que era más o menos la mitad de la ruta- el camino existente era apto para carretas con cargas de 10-15 quintales. De su veredicto se capta que ello era factible y que las condiciones de los terrenos eran superiores a las de la ruta por Sarapiquí.

Un hecho que amerita resaltarse es que von Bülow consigna como "el más bello adorno de la cordillera [...] un volcán tal vez el más alto de Costa Rica, que se parece mucho al de Fuego de Guatemala [...] que merece llamarse el volcán de Costa Rica". Agrega que "no se encuentra en ningún mapa este volcán", y especula que algunos viajeros posiblemente lo confunden con el Miravalles. Por su ubicación y forma cónica casi perfecta, como la del citado homólogo guatemalteco, no cabe ninguna duda de que se refería al majestuoso volcán Arenal, considerado como un cerro hasta su erupción de 1968; por cierto, en tres mapas elaborados posteriormente, y que se mencionarán después, se le denomina Cerro de los Guatusos.

Ahora bien, en cuanto al río como tal, von Bülow le calculaba una extensión de 15 leguas desde Muelle hasta su desembocadura, con riberas más bien altas y sin señales de inundación, aunque en la estación lluviosa las aguas pudieran subir hasta 2,5 a 3 metros de lo normal; asimismo, se iba ensanchando poco a poco hacia la desembocadura, hasta alcanzar valores de 70 a 170 metros de amplitud. En su curso había islas de 2 a 5 manzanas de extensión, que culminaban con la isla San Carlos, en la boca del río, "con unas cuatro y media manzanas de tierra buena y fértil".

El piso de sus riberas estaba "espesamente cubierto de grandes árboles de toda especie", a lo cual von Bülow agrega que dichas riberas "son de sumo aprecio para la cultivación de muchos frutos, hallando en todas partes un terreno sólido y fértil, cuajado de buenas maderas y a orillas de un río navegable perfectamente, y abundoso de peces de toda clase". Asimismo, "cerca del río se encuentran algunos platanillales". Finalmente, de manera algo tangencial acota que cerca del río "se encuentran indicios de plata y oro".

Es interesante destacar que el informe de von Bülow, realizado como una especie de consultoría profesional, aparece fechado el 29 de abril de 1854, y refrendado el 5 de mayo por Florentino Zeledón Mora, por la Secretaría de la Dirección de la Compañía de San Carlos. Sin embargo, cuatro meses después el presidente Mora lo nombró como Superintendente, como se indicó previamente ${ }^{6}$. 
Además, en esa misma fecha se designó a su paisano Bruno von Natzmer como comandante de una guarnición militar en la isla de Providencia, la misma isla denominada San Carlos en el informe de von Bülow, la cual, debido a que "domina tanto la Boca del San Carlos cuanto la navegación del San Juan, es en mi concepto un punto muy importante para Costa Rica". Por cierto, muy pocos días antes de su nombramiento, von Natzmer, junto con Carlos von Bülow - sobrino del barón-, había solicitado a Manuel Alvarado Barroeta, Intendente General, que se nombrara a un agrimensor para medir un inmenso terreno baldío que ellos pretendían denunciar; tal predio correspondía a todo el vértice izquierdo de la boca del río San Carlos, delimitado por dicho río por el este, el San Juan por el norte, y "una cordillera llamada Cerros de San Carlos" por el oeste y el sur. ${ }^{7}$

Según von Frantzius, fue el propio von Bülow quien recomendó establecer la guarnición militar antes citada, lo cual tiene lógica, debido a su valor estratégico o geopolítico. Cabe recordar que entonces estaba en su apogeo la fiebre del oro en California, iniciada en 1849, y por el río San Juan transitaban de manera continua los vapores de la Compañía Accesoria del Tránsito, propiedad del comodoro Cornelius Vanderbilt que transportaba a los aventureros que se dirigían allá, provenientes de la costa oriental de los EE.UU., en busca de fortunas rápidas.

No obstante, la guarnición duró pocos meses debido a que, en cierto momento, von Natzmer solicitó y recibió por adelantado el salario suyo y el de sus subalternos, para cuatro meses; pero no les pagó, se apropió del dinero y en diciembre se marchó a la capital, a pedir más dinero. Denunciado, poco después fue capturado y encarcelado, pero logró huir. Obviamente, esto provocó que el trámite para adquirir el terreno en San Carlos abortara. En Hilje (2009a) se recapitula cómo, tras escapar hacia Nicaragua y Honduras, terminaría enlistándose en las filas filibusteras, donde escaló con astucia, hasta alcanzar una posición prominente, al punto de que lideró uno de los batallones en la célebre batalla de Rivas, en Nicaragua, el 11 de abril de 1856, y tuvo una fuerte cercanía con Walker hasta los meses finales de la vida de este.

Para retornar a la situación de la región de San Carlos, permaneció en el olvido y no fue sino justamente cuando sobrevino la guerra contra el ejército filibustero, que retomó importancia por su valor estratégico. Fue la necesidad de atacar por sorpresa a un destacamento enemigo que había en La Trinidad, en la confluencia de los ríos Sarapiquí y San Juan, lo que obligó a ingresar a este último por el río San Carlos.

Puesto que se desconocía cómo hacerlo, en noviembre de 1856 el gobierno encargó a una comitiva, encabezada por Pío Alvarado, efectuar una inspección de la zona, pero después de 23 días las labores tuvieron que interrumpirse, víctimas los exploradores de la furia de los indios guatusos. No obstante, al retirarse los agobiados expedicionarios, se toparon con una tropa de 200 hombres encabezada por el mayor Máximo Blanco Rodríguez, que a inicios de diciembre había emprendido un viaje de Alajuela hasta Muelle por una pésima trocha de montaña, en cuyo periplo pasaron por Laguna (en Zarcero), el río La Vieja, Los Mancos, el río Ronrón, Peje y el río Platanar.

Esa misma ruta fue recorrida dos semanas después por un contingente de unos 500 hombres, al mando del general José Joaquín Mora Porras. Un dato revelador que consta en el diario de un oficial anónimo de esta segunda misión militar, el cual aparece transcrito en Montúfar (2000), es que:

... a legua y media del Platanar, a la orilla del San Carlos, está un gran rancho del señor don Victoriano Fernández, en el cual viven nuestros carpinteros de ribera, que trabajan por aquellos sitios. Hay allí un desmonte y una pequeña 
plantación de cacao. El lugar es cómodo, ventilado y pintoresco, pero cercano al raudal del Lagarto, por cuya razón han preferido el desembarcadero actual distante media legua.

Es decir, esto no solo denota la presencia de Fernández en la zona, sino que también indica con exactitud dónde vivía. En el mapa de von Bülow, de dos años antes, en secuencia aparecen mencionados el estero Lagarto, el río Platanar, el estero Camastro y el Muelle Victoriano.

Cabe suponer que los carpinteros ahí destacados fueron los encargados de construir las balsas y botes que días antes permitieron al mayor Blanco y su tropa navegar hasta La Trinidad, donde se libró la célebre batalla del 22 de diciembre, con la que se inició el final de Walker, quien se rendiría cuatro meses después en Rivas, Nicaragua, el $1 .^{\circ}$ de mayo de 1857 . Asimismo, en el citado diario, se anota que dos días antes, al pernoctar en Peje, hallaron "una hacienda que empieza a formar don José María Rodríguez. El General se alojó en el rancho de la hacienda, y alrededor, en los corrales y desmontes vecinos se colocaron las tiendas [de campaña] de la gente". O sea, en aquellas agrestes soledades, para entonces Fernández ya contaba con al menos un vecino.

Figura 1. Región de San Carlos, en el mapa de la región norte publicado por von Frantzius en 1861 Fuente: Marcos Hernán Elizondo.

\section{Los primeros mapas}

Un detalle interesante es que von Frantzius se atrevió a elaborar un mapa de la región norte del país, el cual publicó en 1861 en Alemania ${ }^{8}$. Sin embargo, no la recorrió ni la conoció en detalle, debido a sus ocupaciones como médico y a su maltrecho estado de salud, víctima del asma que padecía desde joven. (Hilje, 2013).

En cuanto a la zona de San Carlos, en dicho mapa (Figura 1) se percibe la presencia del río Balsa como si fuera el origen del río San Carlos, en el que después vierten sus aguas el Tapezco, La Vieja, Ronrón, Peje, Platanar, San Rafael y Cooper por el sector oriental, más los ríos Arenal y Peñas Blancas por la margen occidental ${ }^{9}$. En realidad, el río San Carlos se origina de la fusión del Jabillo y el Peje; además, de manera errónea von Frantzius traza el curso del río Arenal al sur del Peñas Blancas. Pero, aparte de las entendibles imprecisiones en la ubicación, longitud y forma de los cauces de estos ríos, es inexcusable la ubicación de El Muelle, que colocó muy al

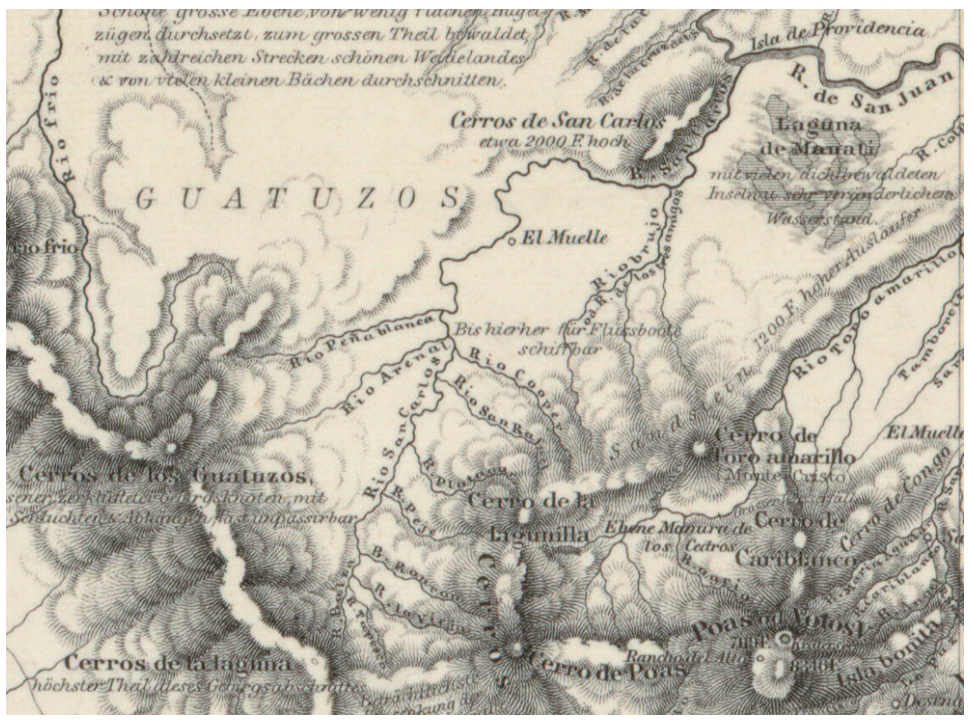
norte de la confluencia de los ríos San Carlos y San Rafael.

Además, en el citado mapa denomina Cerro de la Lagunilla — distinto de los Cerros de la Laguna, algo lejanos hacia el occidente- a la masa montañosa cerca de la cual reposa hoy Ciudad Quesada (a $656 \mathrm{~m}$ de altitud), que en un mapa ulterior suyo, de 1869, Ilama Cerro de la Vieja. En realidad, por su visibilidad e imponencia, más bien pareciera tratarse del volcán Platanar (a $2183 \mathrm{~m}$ ), hoy inactivo y a $8 \mathrm{~km}$ al sureste de dicho poblado, y que algunos llaman volcán Congo ${ }^{10}$; las partes altas del Platanar están dentro del Parque Nacional del Agua Juan Castro Blanco. Por cierto, en este último mapa von Frantzius omite 
algunos de los ríos citados, así como la localidad de Muelle, y enmienda la localización del curso del río Arenal en relación con el río Peñas Blancas.

A propósito de mapas, merece una mención especial uno que data de 15 años después, basado en varias fuentes. Se trata de la Carta geográfica de la República de Costa Rica (Centro América), elaborada por Luis Friederichsen (1841-1915) en 1876, en Hamburgo, Alemania (Figura 2). Él era el primer secretario de la Sociedad Geográfica de Hamburgo. Según consta en una leyenda que aparece al pie del mapa, le fue encargado por el alemán Guillermo Nanne Meyer, residente en nuestro país y, por entonces, Director General del Ferrocarril de Costa Rica, empresa del magnate estadounidense Minor $C$. Keith.

Trazado en una escala de 1: $500000(1 \mathrm{~cm}=5 \mathrm{~km})$ según la citada leyenda, se basó en:

... los mapas del Almirantazgo inglés y americano, y los datos y estudios topográficos de los Señores Ingenieros del Ferro-Carril, del Profesor Don Carlos von Seebach, Doctor Don Alejandro von Frantzius, Profesor E. Mellis, Ingenieros Dahser, Kurtze, Rünnebaum, Endrées, Lacroix y Beyer en los años 1871-1875, bajo la administración del Excelentísimo Señor Presidente General Don Tomás Guardia"1.

Al respecto, conviene acotar que el alemán Franz Kurtze residió por casi 20 años en nuestro país, hasta su muerte en 1869; el naturalista alsaciano Auguste R. Endrés lo hizo por poco más de siete años, entre 1867 y 1874; y el geólogo alemán von Seebach por un año, entre 1864 y 1865. De ellos, Endrés recorrió con frecuencia la región de San Carlos, pues trabajó ahí entre 1867 y 1868 como ingeniero - aunque no tenía esa formación- en la construcción del nuevo camino, entre Los Ángeles de San Ramón y Muelle, el cual seguía una ruta parecida a la actual, por el Bajo de los Rodríguez (Ossenbach et al., 2013).

Un hecho que llama la atención en el mapa de Friederichsen es que la única localidad consignada para San Carlos es Muelle Victoriano. Sin embargo, una inspección minuciosa del mapa revela que esa localidad figura en la margen izquierda y no en la derecha del río San Carlos - e incluso un poco al norte de la confluencia de los ríos San Carlos y San Rafael-, cuando lo cierto es que se localizaba al sur del verdadero Muelle, a juzgar por el inobjetable mapa de von Bülow de dos decenios antes. Cabe acotar que Friederichsen nunca visitó Costa Rica y trabajó con los datos que le enviaron, algunos erróneos, obviamente.

Ahora bien, en el curso de los años, la región de San Carlos se iría poblando, tanto con nacionales como con extranjeros que hicieron denuncios en aquellos inmensos, planos y fértiles terrenos, por entonces cubiertos con tupidas montañas. De gran significado fue el hecho de que para 1884 se establecieran allí los hermanos José Joaquín y Baltazar Quesada Rodríguez, junto con

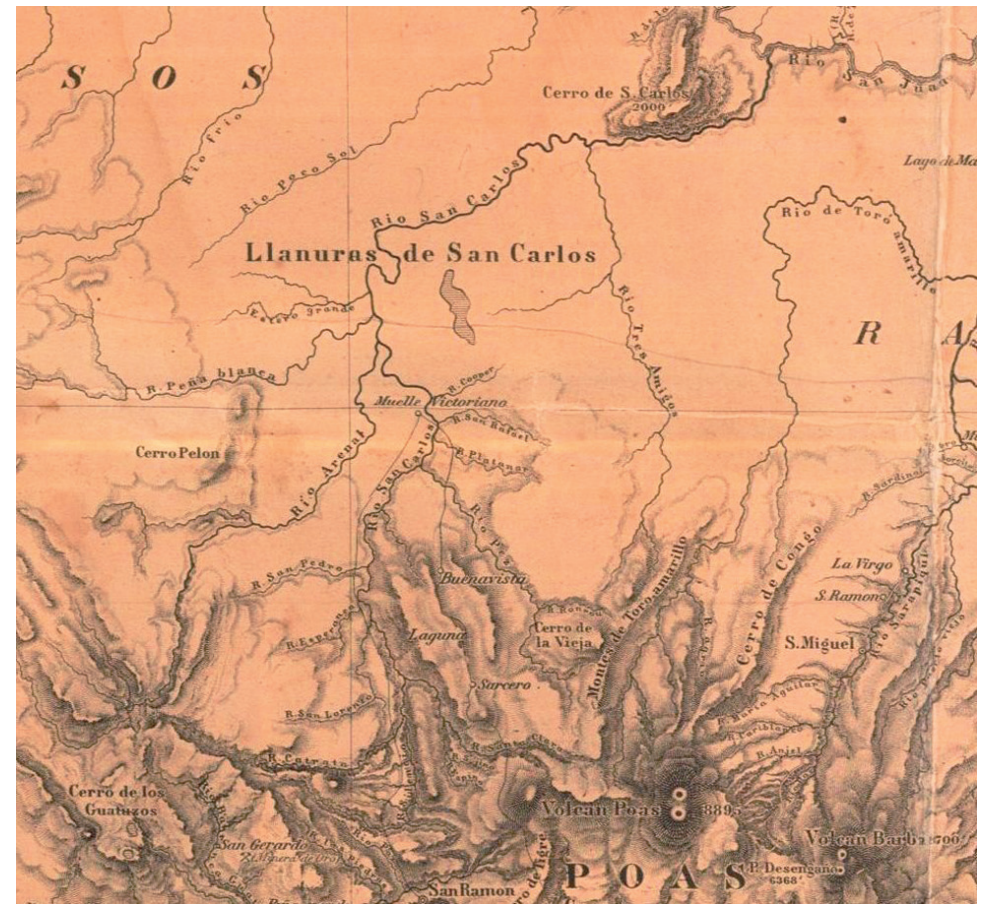


José María Quesada Ugalde. Estos pioneros se afincaron en un punto de las estribaciones del volcán Platanar, que con los años se pobló con otras familias, para dar origen al caserío de La Unión, núcleo fundacional de Villa Quesada, el principal pueblo de las llanuras del norte de Costa Rica por muchos años. Conocido ahora como Ciudad Quesada, es un conglomerado humano de gran pujanza económica, otrora gracias a la ganadería y a la agricultura y hoy también al turismo ${ }^{12}$.

\section{La presencia del Dr. Guzmán}

En el segundo semestre de 1891, nuestro país fue invitado a participar en la Exposición Universal de Chicago, la cual se efectuaría en 1893, en conmemoración del cuarto centenario del descubrimiento de América por parte de Cristóbal Colón; esto justificó que en inglés se le denominara World's Columbian Exposition (Exposición Universal Colombina). Para ello fungió George Percival Scriven como Comisionado Especial, quien designó a su paisano Luis Chable como agente local de la Exposición. Esta actividad ocurrió durante la administración del abogado José Joaquín Rodríguez Zeledón (1890-1894), cuyos designados o vicepresidentes eran los médicos Pánfilo Valverde Carranza y Carlos Durán Cartín, así como el maestro, comerciante y político herediano Joaquín Lizano Gutiérrez.

Si bien en Costa Rica residían naturalistas de la talla de Henri Pittier, Paul Biolley, Adolph Tonduz, George K. Cherrie y Cecil F. Underwood -e incluso en 1887 se había fundado el Museo Nacional-, el gobierno decidió contratar al salvadoreño David Joaquín Guzmán Martorell (Figura 3) como coordinador de la citada iniciativa ${ }^{13}$.

Cabe acotar que Pittier colaboró recolectando plantas al sur del país, en los territorios de Térraba y Boruca, y de manera ocasional también lo hicieron Secundino Orozco Salazar y Richard Pfau. Orozco, profesor de secundaria en ciencias naturales y radicado en Alajuela, era un asiduo recolector para el Museo Nacional, en tanto que Pfau era un reconocido maestro-jardinero suizo que residía en la capital; por cierto, Orozco recolectó 789 especímenes de insectos para la Exposición, los cuales fueron exhibidos sin la debida clasificación, según consta en un voluminoso catálogo preparado por Guzmán para dicho evento (Guzmán, 1892a) (Figura 4A); dicho documento fue complementado con un amplio apéndice (Guzmán, 1892b) ${ }^{14}$.

Fue el 7 de diciembre de 1891 que se acordó establecer una oficina dirigida por Guzmán, con el objetivo de "colectar, organizar y clasificar todos los productos naturales y elaborados, los objetos de arte y manufacturas, y todo lo relativo a ciencias y adelanto intelectual existente en la República". A dicha oficina se le dotó de un presupuesto adecuado, así como de una sede, papelería oficial y un sello específico para identificar sus documentos (Figura 4B, 4C).

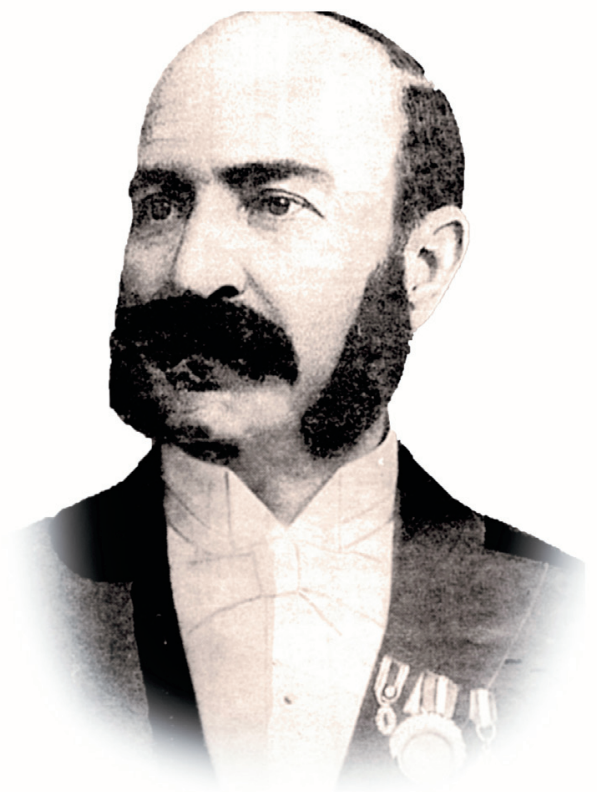



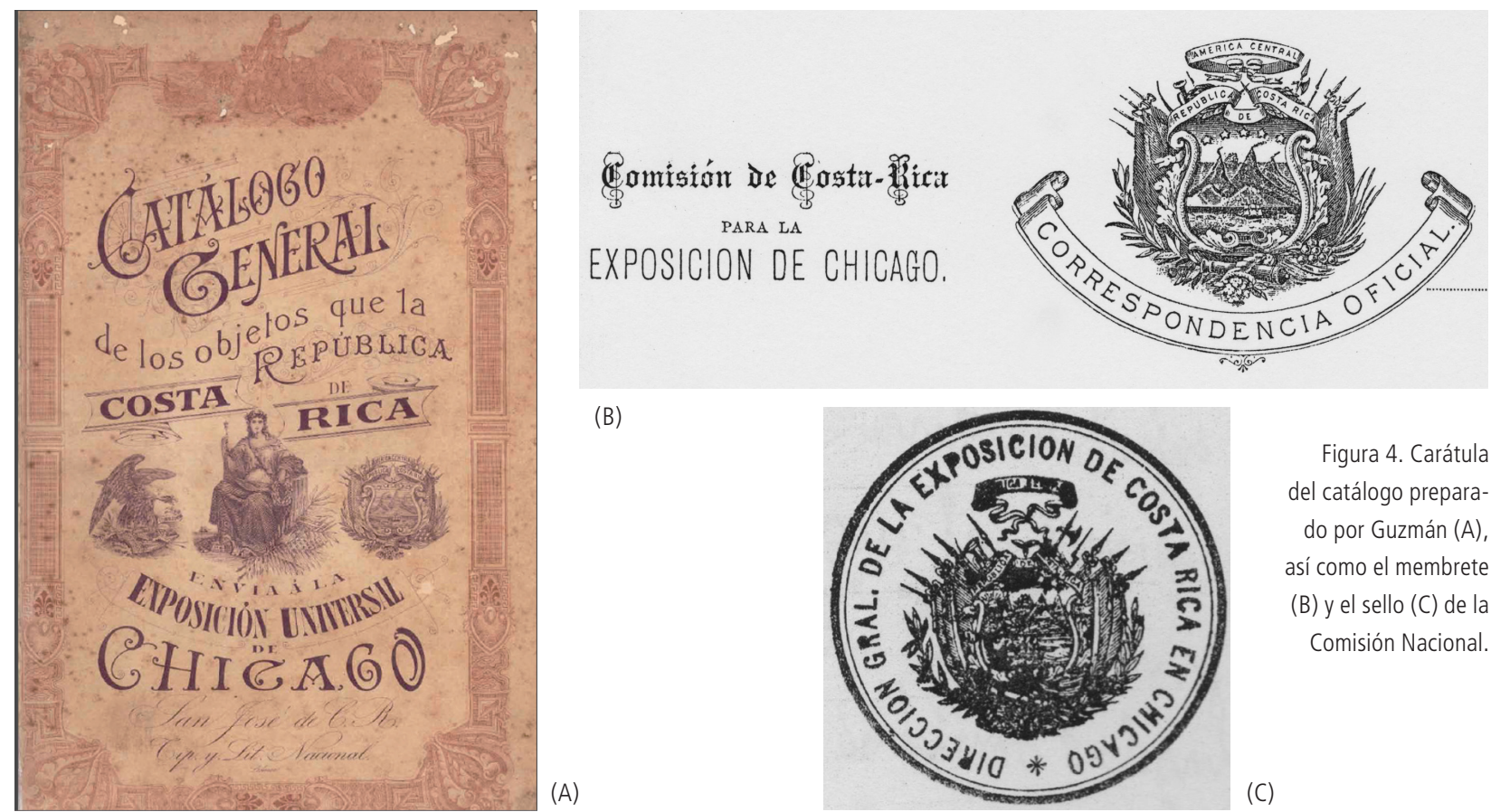

(B)

(A)

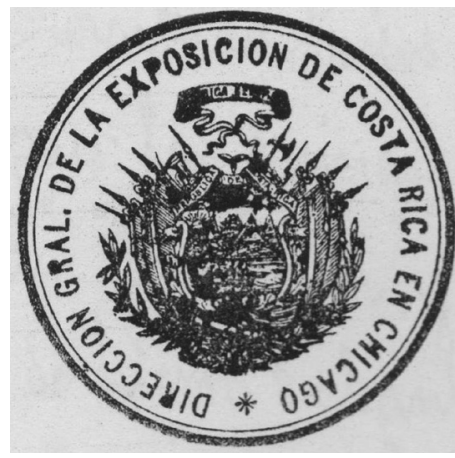

Figura 4. Carátula del catálogo preparado por Guzmán (A), así como el membrete (B) y el sello (C) de la Comisión Nacional.

Nacido en 1843 y formado como médico en la Universidad de París, tuvo una activa vida científica y política en su país, lo que pagó con el exilio durante el mandato del general Carlos Basilio Ezeta ${ }^{15}$. Arribó a Puntarenas en 1890 — donde ejerció su profesión-y en enero de 1892 se mudaba a San José para asumir sus nuevas labores, cuando frisaba los 48 años de edad.

El motivo de su contratación podría haber obedecido a que los citados científicos tenían numerosas tareas que atender, en tanto que Anastasio Alfaro, director del Museo Nacional, por entonces efectuaba una pasantía en el Instituto Smithsoniano, para conocer el modus operandi de sus museos y valorar cómo aplicarlo al nuestro. Además, aunque no era botánico, zoólogo ni geólogo, sino más bien un aficionado en estas disciplinas científicas, Guzmán tenía experiencia en exposiciones internacionales, al punto de que - en sus propias palabras - expresaba que había acumulado valiosa experiencia "en siete exposiciones universales a que he cooperado y he asistido como Delegado y Comisionado de otros gobiernos de Centro-América".

Nomás a inicios de febrero, preparó e hizo circular un instructivo para "facilitar, tanto a las autoridades como a los particulares, la manera de colectar los objetos que esta Comisión necesita para organizar a su vez todo el conjunto del concurso de Costa Rica en aquella gran fiesta de la civilización". Su expectativa era recolectar unas 5000 o 6000 muestras, en 10 departamentos del país para clasificarlas en 57 grupos y 167 clases, según la normativa de la Exposición.

Por tanto, el 25 de febrero partía hacia Puntarenas (Esparza, Puntarenas y Golfo Dulce), acompañado por un ayudante y un fotógrafo, para continuar su periplo de 43 días por Guanacaste (Nicoya, Santa Cruz, Liberia, Cañas y Bagaces), algunos cantones de Alajuela (Atenas, San Mateo, San Ramón, Naranjo y Grecia) y Heredia (no indica cuáles cantones), y regresar a la capital el 10 de abril.

Llama la atención que en su extenso informe de 15 páginas haya apenas una mención de la flora observada, en medio de abundante información sobre aspectos mineros y geológicos ${ }^{16}$. En esa única cita consta que: 
Cerca de las márgenes del [río] Tempisque, cerca de su nacimiento, se encuentran extensos bosques de balsamares o chirraca que producen el precioso bálsamo negro, tan usado en medicina y perfumería; allí mismo, sobre los árboles que forman eterna y sombría bóveda de verdura, se encuentran la trepadora vainilla, la zarzaparrilla, árboles preciosos como el granadillo, el cocobola, la caoba, el meloncillo, el ñambar, el ronrón, el níspero, laurel, cortés, marío y otros muchos.

Es oportuno mencionar que de la corteza de la chirraca, también denominada bálsamo negro, bálsamo salvadoreño y bálsamo de Perú (Myroxylon balsamum), se extrae una resina utilizada como estimulante respiratorio y como incienso, al igual que en perfumería. Por su parte, la vainilla (Vanilla planifolia) es una orquídea de cuyo fruto se extrae un conocido saborizante, y las raíces de la zarzaparrilla (Smilax regelii o $S$. vanilliodora) aportan un producto consumido como refresco y con fines medicinales.

En cuanto a los árboles citados, sus nombres científicos son: granadillo (quizá Dalbergia sp. o Lonchocarpus sp.), cocobola o cocobolo (Dalbergia retusa), caoba (Swietenia macrophylla), ñambar (Platymiscium parviflorum), ronrón (Astronium graveolens), níspero (Manilkara chicle) y laurel (Cordia alliodora). El meloncillo quizás sea alguna de dos especies denominadas melón, que crecen ahí: Agonandra macrocarpa (Opiliaceae) y Schoepfia schreberi (Olacaceae); el cortés podría referirse al cortez amarillo (Tabebuia ochracea) o al cortez negro (Tabebuia impetiginosa); y el marío podría ser Gymnanthes riparia o incluso el maría (Calophyllum brasiliense), que aunque no es de zonas secas, a veces aparece en la ribera de los ríos, ya que las semillas se desplazan por el agua desde la Cordillera Volcánica de Guanacaste ${ }^{17}$.

Cabe acotar que en este informe especifica haber recorrido unas 760 millas, tomado 235 fotografías y establecido 17 comisiones de colaboradores, de los cuales se esperaría que recolectaran 1724 objetos; para ello dispuso de un presupuesto de 2580 pesos. Asimismo, ahí indica que:

... después de esta primera exploración efectuaré otra al valle de San Carlos y su río, visitando las extensas Ilanuras de los Guatuzos [Guatusos], sus selvas vírgenes, las márgenes de los ríos Frío, Poco Sol [Pocosol] y Platanares; lugares, según datos, de extremada fertilidad, donde, como en una tierra de promisión, se dan los más variados e importantes productos vegetales y animales.

A continuación anuncia que "otras exploraciones dirigiré hacia Talamanca, Comarca de Limón, Puriscal, Dota, Aserrí y Térraba", pero sin destacar ninguna peculiaridad acerca de estas localidades. Lamentablemente, no hay información disponible acerca de dichas exploraciones, quizás porque se extravió, exceptuando la de San Carlos, a la que se aludirá pronto.

En cambio, abundan los detalles referidos a aspectos administrativos de la Exposición, gracias al flujo de correspondencia con el abogado José Vargas Montero, Ministro de Fomento, e incluso se cuenta con una fotografía del pabellón que albergó las muestras recolectadas (Figura 5).

De esa información conviene resaltar algunos aspectos importantes. Por ejemplo, por orden de nuestro Gobierno se decidió establecer en Chicago una Comisión Nacional que atendiera todos los asuntos de la Exposición. Quedó integrada por el diplomático Manuel María Peralta Alfaro (Presidente), David J. Guzmán (Vicepresidente y Comisario General), el diplomático Joaquín Bernardo Calvo Mora (Secretario) y el naturalista Anastasio Alfaro González (Prosecretario y Comisionado Especial de la Sección Arqueológica). 


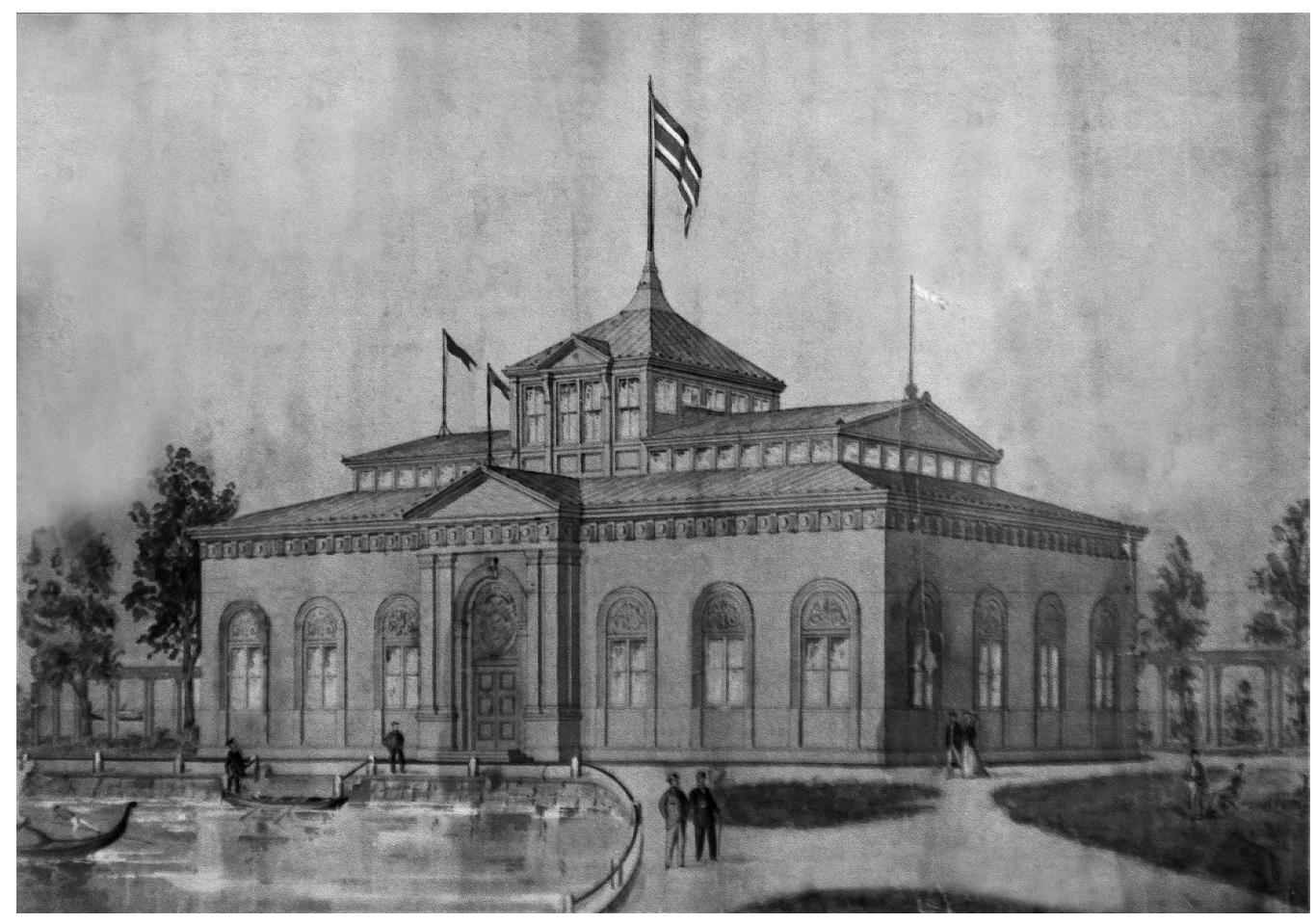

Figura 5. Pabellón de Costa Rica en la Exposición de Chicago.

Cabe indicar que Alfaro se trasladó ahí desde el Instituto Smithsoniano, ente que incluso prestó centenares de ejemplares de sus valiosas colecciones de aves costarricenses para que fueran exhibidas, además de cubrir los gastos de embalaje y transporte de todo este material; aunque en una carta de Alfaro se anota que fueron 500 ejemplares, en el catálogo preparado por Guzmán consta que fueron 692 los especímenes facilitados.

Realizada en Jackson Park, en un área de 278 hectáreas, la Exposición se extendió por seis meses - del $1 .^{\circ}$ de mayo al 30 de octubre de 1893- con la presencia de unos 50 países, entre los cuales figuraron el caribeño Haití y los latinoamericanos México, Guatemala, Colombia, Venezuela, Brasil, Uruguay y Argentina. Concurrieron más de 27 millones de personas y nuestro pabellón fue visitado por unas 12000 personas por día. Como un detalle interesante, en nuestro pabellón se incluyó la degustación de café $y$, con tal éxito que, por ejemplo, solo durante agosto se vendieron 94365 tazas, a \$ 0,10 cada una, lo cual dejó una ganancia neta de \$ 6200 y un merecido reconocimiento por la alta calidad de nuestro café.

Aparte de estos logros, se obtuvieron varios premios y, más relevante aún, la pequeña Costa Rica alcanzó una importante proyección mundial, como había sucedido en la Exhibición Universal de Londres, en 1862, la primera de magnitud planetaria en la que participó nuestro país y en la que desde aquí colaboró el naturalista von Frantzius.

En fin, este es el marco histórico que permite entender, en su debido contexto, el motivo por el cual Guzmán emprendió un importante viaje por la región de San Carlos para recolectar muestras de flora y fauna, así como productos naturales y manufacturas, y así exhibirlas en Chicago. 


\section{El relato de Guzmán acerca de San Carlos}

Es muy curioso que en ninguno de los expedientes atinentes a la Exposición Universal de Chicago haya algún informe sobre el viaje de Guzmán por San Carlos, lo cual podría deberse a extravío accidental o sustracción. Pero llama la atención que se le diera tal importancia que, muy poco después de enviado al Ministro de Fomento, fuera reproducido en la prensa, a diferencia del informe relativo a Puntarenas y Guanacaste ${ }^{18}$. La posible explicación reside en la importancia geoestratégica de esta región, por lo que el gobierno tenía mucho interés en publicitar sus riquezas.

De hecho, según se capta en el catálogo (Guzmán, 1892a), el gobierno había firmado un contrato el 3 de agosto de 1888 con el empresario Minor C. Keith para construir un ferrocarril en la zona, como un ramal del ferrocarril entre Puerto Limón y la capital. Además, en esa misma fecha se pactó una concesión entre nuestro gobierno y la Asociación del Canal de Nicaragua, cuyas obras ya se habían iniciado para 1892. A esto se sumaba un contrato para el establecimiento de una colonia de inmigrantes suecos o noruegos "que se establezcan en los baldíos de la comarca de San Carlos", bajo la tutela del sueco Carlos Berggren, cuyo texto completo aparece en el citado catálogo.

Ahora bien, aunque en su informe no consta el período durante el cual transcurrió su viaje, en uno de los expedientes disponibles aparecen varios documentos esclarecedores. Por ejemplo, fechado el 18 de abril de 1892, en tan solo un folio aparece el Presupuesto de la exploración al Río San Carlos y territorios contiguos, por un monto de 2086.50 pesos. Los rubros incluyen el pago de cabalgaduras y los viáticos para cuatro personas, la compra de productos vegetales y animales, los fletes para el transporte de dichos productos en carretas, las habilitaciones (montos entregados por anticipado a algunos colaboradores clave) y otros gastos menores.

Otros elementos de la travesía se pueden reconstruir a partir de las facturas o recibos que, confeccionados a mano, aparecen en el citado expediente. Así, todo sugiere que la expedición se inició el 20 de abril, pues la víspera Guzmán había adquirido en la tienda de Teodosio Castro "un carriel de viaje", una maleta de cuero con numerosos compartimentos o bolsillos apta para depositar múltiples objetos de diverso tamaño. El día 20 la comitiva viajó a Heredia, quizás por tren. Ese día, según consta en un recibo por 110 pesos - aunque el monto real era de 160 pesos-, arrendaron a Julio Sánchez cuatro "bestias para San Carlos" por 40 días, a razón de un peso diario. El grupo avanzó hasta Alajuela, donde pernoctó en el hotel de Ventura Cordero, a quien le alquilaron cuatro cabalgaduras más, por 23 días, y además le pidieron conseguir un mozo para que les ayudara durante la expedición.

Una factura revela que la noche del día 21, ya en Grecia, se hospedaron en un hotel, cuyo dueño o administrador era Nicolás Caparroso, y al día siguiente estaban en Naranjo, donde "por súplica de Rafael Vargas Chaves" cancelaban a David M. Romero Castellanos "la suma de quince pesos, como alquiler de una bestia para ir a San Carlos"; asimismo, el día 23, entregaba 200 pesos a Rafael Rodríguez Madrigal, Jefe Político, "para colectación de productos en el cantón de Naranjo" ${ }^{19}$. Posteriormente, en Zarcero, cancelarían a Hermenegildo Ramírez el monto correspondiente a comida para los exploradores y el "potreraje para bestias"; es decir, la estadía de la tropilla en algún pastizal cercano. Quizás pernoctaron ahí el día 23, aunque no se cuenta con facturas para comprobarlo.

Es posible que arribaran a San Carlos el día 24, pero no hay evidencias al respecto. Eso sí, el día 25 Guzmán aportaba 200 pesos al alemán Teodoro Koschny "para los gastos que se harán en el cantón de San Carlos, como pago parcial a los gastos generales que ocasionará esta colección de objetos destinados a la exposición". Cabe pensar que, por facilidad, ellos se hospedaron en la casona de dos pisos que este alemán tenía en San Rafael (Figura 6). 


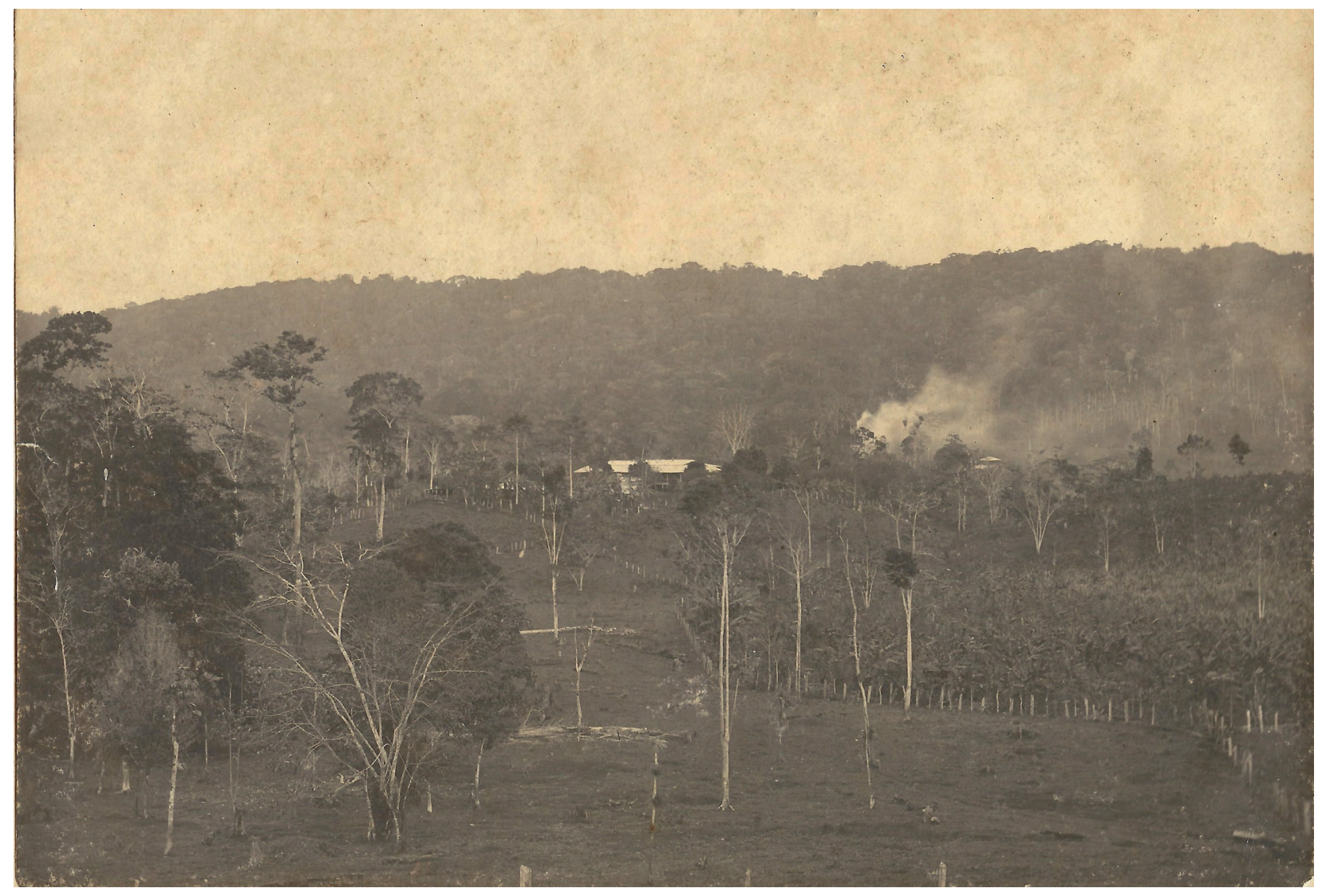

Encomendada a Koschny la tarea de recolección para las semanas y meses venideros, la comitiva emprendió la navegación por el río. De ello es evidencia la cancelación de 365.75 pesos a José González "por una embarcación aperada con sus respectivos marineros y provisiones por ocho días en el reconocimiento del Río San Carlos, del Muelle S. Rafael al resguardo de la Boca del Río". Es posible que hicieran ese recorrido a partir del propio día 25 y -como les tomó ocho días efectuarlo- ya estuvieran de regreso el 2 de mayo.

Esto permite entender que, con fecha del día siguiente, haya una factura por 120 pesos a nombre de Mario Camargo, "por unos sacos de hule, y daños causados en un arrozal por las bestias de la Comisión". Es decir, en ausencia de sus amos provisionales y tras tantos días de soledad, la hambrienta tropilla no resistió la tentación de invadir y estropear un reluciente campo de arroz, al deleitarse devorando las suculentas macollas, mientras pisoteaba el anegado terreno.

Se ignora la fecha en que partieron de regreso, aunque el 5 de mayo se le pagó a C. Mondragón en Buenavista, a favor de Mercedes Zumbado, el monto correspondiente a la alimentación del grupo y de la recua. Asimismo, en Tapezco se le entregaron 150 pesos a Mondragón, para Ramón Mercedes Rodríguez, por la compra de madera para confeccionar unos cajones para almacenar muestras de plantas de San Carlos. Cabe suponer que estas cajas fueron llevadas a Koschny después.

Ese mismo día la comitiva llegó a Naranjo, donde al ya citado David M. Romero se le pagaron 150 pesos por la confección de cajones para guardar plantas y otros objetos; asimismo, a él se le cancelaron 44 pesos, pertenecientes a Fidel Artavia, "por 45 días de servicios domésticos en la expedición a San Carlos", más la alimentación del grupo en Naranjo. Además, el día 6 se le saldaba a la empresa Faustino Vargas \& Co. un monto por ropa y otras mercaderías. 
Es de suponer que ya para el día 8 estaban de regreso en la capital, lo que sumaría 19 días de excursión, pero quizás aprovecharon para recolectar o encargar algunos objetos entre Naranjo y Heredia, pues retornaron después de esa fecha. De hecho, en un documento fechado el 12 de mayo el propio Guzmán reclamaba un monto de 210 pesos, correspondiente al diario (viáticos) de tres miembros de la Comisión, "por 23 días". Y, finalmente, ya en la capital, Guzmán se dedicó a organizar la información recabada para redactar el informe de su viaje, que está fechado el 15 de mayo de 1892.

Como una curiosidad, Guzmán prescindió de su planeada visita a los dominios de los indios guatusos, debido a lo henchidos que estaban los ríos en la época en que recorrió San Carlos. A su manera, y de manera previsora, en una localidad no indicada adquirió, en el negocio de Matilde Vallejos, "provisiones y artículos para ofrecer a los indios guatusos", tales como 30 varas de mecate de manila, dos litros de aguardiente, una botella de agua florida, dos paquetes de fósforos, un par de chinescos de vidrio, un peine, agujas y 12 pañuelos. Es de suponer que lo hizo para ganarse su confianza, de modo que le ayudaran en sus faenas de recolección de objetos. Cabe indicar que hoy esta etnia está constituida por unas 1000 personas, que conviven en un territorio de casi 3000 ha, concentradas en los palenques de Margarita, Tonjibe y El Sol.

Antes de proseguir, conviene hacer una digresión a propósito de Teodoro Koschny, pues fue un colaborador clave para el éxito de las labores encomendadas a Guzmán por nuestro gobierno.

Llegado a Costa Rica antes de 1869, con apenas unos 24 años de edad, en 1870 y de manera fallida, Koschny intentó implantar en el Caribe la colonia agrícola Nueva Silesia, para traer unas 100 familias alemanas (Hilje, 2009b). Después de trabajar en un predio agrícola capitalino con el peruano Francisco Otoya Seminario - casado con la alemana Magdalena Ernst- y hasta fungir como preceptor de sus hijos, enfrentó varias dificultades personales.

En 1877 hizo denuncios en San Rafael y Cooper de San Carlos, pero se ignora cuándo se instaló allá, aunque cuando Guzmán pasó por ahí, ya era un próspero hacendado. De hecho, para esos años tenía una finca de más de 1000 manzanas, con repastos para el ganado, siembras de piña y banano, así como áreas de bosque de cuyos árboles de hule extraía caucho. Era en San Rafael que estaba su casona y, con los años, su hacienda se convertiría en el núcleo de un poblado llamado Koschny, ahora denominado San Rafael de Platanar. Casado primero con María Peñaranda Rojas y después con Juana Cascante Lara, tuvo una amplia descendencia que ha perpetuado el apellido hasta hoy.

Es pertinente acotar que, aunque él no tuvo estudios universitarios en ciencias o agronomía, fue un ingenioso experimentador con plantas y animales, así como un asiduo recolector de plantas que le solicitaban del extranjero, sobre todo de Europa. En reconocimiento a su labor, la palma Malortiea koschnyana y el árbol de fruta dorada (Virola koschnyi) portan su nombre.

Conviene hacer una digresión aquí, en cuanto al poblado hoy denominado Kopper. Según Jorge Rolando Molina, el nombre del río Cooper, llamado antes río de la Navegación, alude a Henry Cooper, quien fue comisionado por el gobierno para efectuar mediciones de los vastos terrenos denunciados por Victoriano Fernández; por cierto, este ingeniero inglés había llegado a Costa Rica cerca de 1825 para trabajar en minería en los Montes del Aguacate y fue el padre del naturalista Juan José Cooper Sandoval. El topónimo Cooper figura tal cual en los dos mapas de von Frantzius, así como en el informe y el mapa de von Bülow, de 1854; además, en el apéndice del catálogo de Guzmán (1892b).

Aunque en San Carlos existe hoy una localidad denominada Kopper, para 1854 no vivía en Costa Rica nadie con dicho apellido; el patriarca de esta familia fue el 
prusiano Arturo Kopper Trischnuth, quien se casó con María Amalia Steffens von Greggart, en Cartago. Fue su hijo Arturo Kopper Steffens, nacido en 1865 en Cartago, quien tras vivir con su familia en Grecia, se estableció en San Carlos cerca de 1895; ahí tuvo fincas e incluso fungió como subinspector del Resguardo Fiscal en Muelle durante el gobierno de Rafael Iglesias Castro (1894-1898) (Quesada, 1958). Después de engendrar una amplia descendencia, con los apellidos Kopper Cubero y Kopper Serrano, murió en marzo de 1954 en Quebrada Azul, a poca distancia de Florencia. Cabe suponer que la notoria presencia de esta familia en la zona, más la similitud de su apellido con el original Cooper, causó una mutación espontánea en la toponimia local, de Cooper a Kopper, hasta afianzarse este último nombre para siempre.

Ahora bien, para retornar a Guzmán, debido a su valor histórico y testimonial, a continuación se transcribe el documento que, con el título Informe sobre el viaje al río San Carlos, fue publicado en el diario oficial La Gaceta una semana después de entregado al gobierno ${ }^{20}$. Debajo del título consta que se trata de un documento asociado con la Comisión de la Exposición de Chicago. Por cierto, con leves modificaciones, este relato apareció en el catálogo preparado por él.

Conviene acotar que al documento que aparece a continuación se le hicieron leves correcciones en aspectos de forma, incluidos entre paréntesis cuadrados o corchetes, además de que, para facilitar su lectura, se dividieron párrafos que eran excesivamente largos. Asimismo, aparte de numerosas notas explicativas anotadas como pies de página, se incorporaron varias ilustraciones pertinentes.

"Señor Ministro de Fomento:

Tengo la honra de informar á Ud. sobre mi última expedición al río San Carlos, en busca de los objetos naturales de esta rica sección de la República.

Extenso campo hay allí para formar, como he formado, un centro activo de colectación, y al efecto he nombrado al señor don Teodoro Koschny, naturalista y hombre de estudio, entregado al cultivo y explotación de una bonita hacienda, situada sobre el río San Rafael, para recoger maderas preciosas, gomas, leches, plantas vivas de ornato, resinas, hule, semillas oleaginosas, bálsamos, plantas medicinales y tintóreas, etc ${ }^{21}$.

La zona de San Carlos encierra maravillas propias tan solo de una naturaleza tropical tan fecunda, en razón de las continuas lluvias y del humus vegetal, formando y amontonado en el transcurso de los siglos en las montañas y extensísimos bosques de la región.

Es necesario, en verdad, haber visto el horizonte sin límites de verdura, algunos productos exuberantes de esta zona, donde reina eterna primavera; haber contemplado sus elevadísimos y gruesos árboles, sus flores admirables y fragantes, sus pájaros de bello plumaje y mágico canto, sus dulces frutas, sus útiles bálsamos y gomas, sus orquídeas, bellezas todas olvidadas en el fondo de un país poco transitado, para declarar esta región, la tierra de verdadera promisión de Costa Rica. Un libro, señor Ministro, sería necesario para describir tan ingentes veneros de riqueza de esta parte de la República.

A partir del último descenso de las montañas o cordilleras de La Vieja ${ }^{22}$, comienzan las extensas Ilanuras o 'Bajos de San Carlos', donde se hallan situadas algunas valiosas haciendas de ganado y también se comienza a trabajar en plantaciones de café y cacao, pues el clima es fresco o templado $\left(22^{\circ}\right.$ a $\left.23^{\circ} \mathrm{C}\right)$. 
Figura 7. Sección del cauce del río, mostrando parte de un playón (A), así como uno de los islotes (B).
(A)
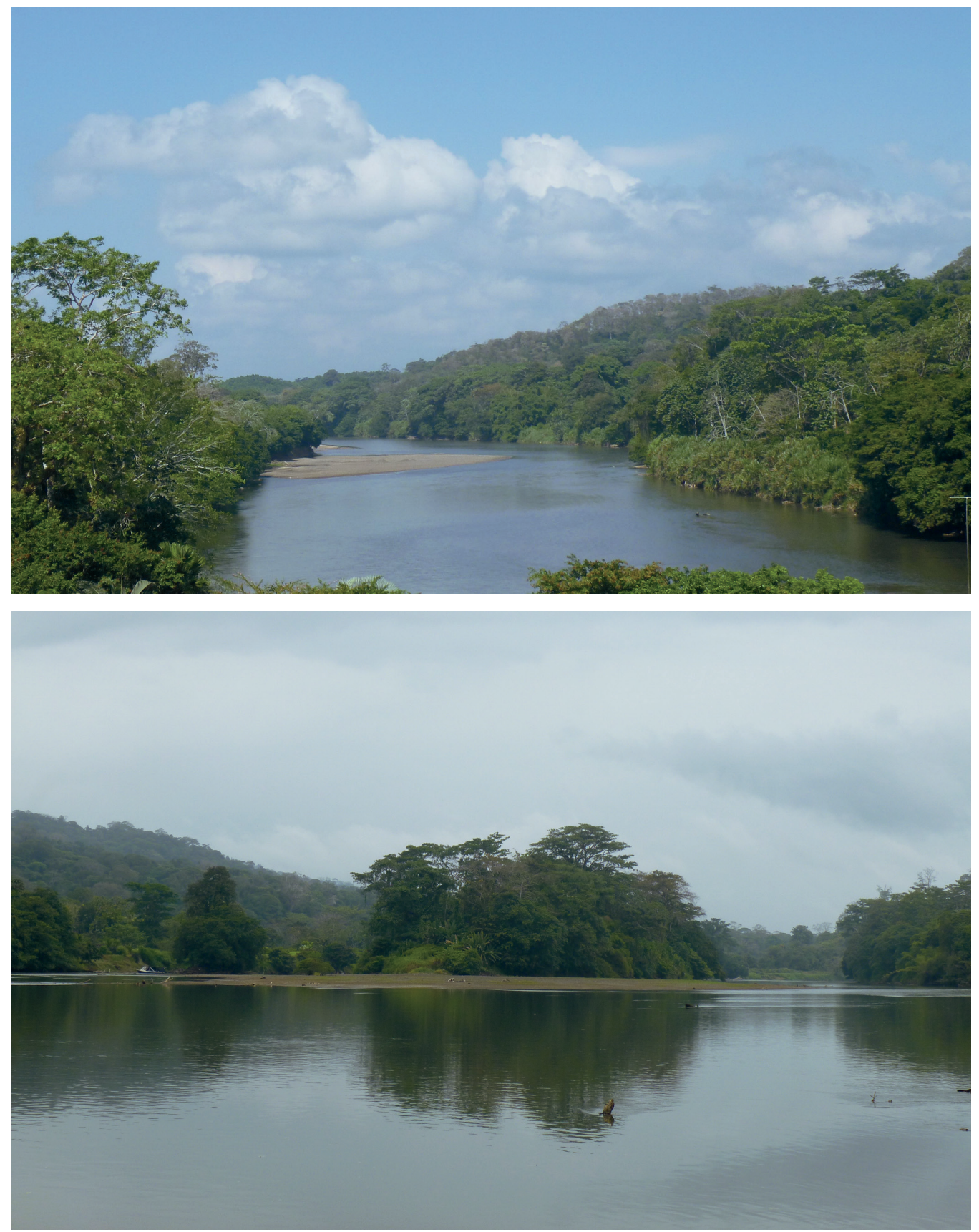

Toda la extensa llanura se inclina hacia el noreste hasta formar la cuenca profunda del San Carlos (Figura 7A), arteria de gran porvenir en la navegación fluvial del país, una vez que se piense en dragar el cauce del río, poco profundo en muchos puntos.

Por observaciones precisas he podido rectificar varias inexactitudes que figuran en el Mapa de Friederichsen, que actualmente sirve en todas las oficinas, señalando las estaciones principales del río, sus diez islotes (Figura 7B), enmendando a la vez la errónea posición de los ríos de Arenal y Peñas Blancas, así como la situación y longitud del cerro de San Carlos ${ }^{23}$. Los islotes a que me refiero se denominan (no están señalados en ningún libro) de la boca del río San Carlos hacia el muelle de San Rafael24: 
las tres Canacas $\left(1^{a}\right.$., $2^{a}$. y $3^{a}$. con una longitud respectiva de 150, 200 y 353 varas), Santa Rita (600 varas), Rosalía (128 varas), Tres Amigos (179 varas), Playa Hermosa (258 varas), Remolinito (79 varas), Corriente de Oro (137 varas) y La Tigra (67 varas) 25 . Todas estas pequeñas islas son abundantes en pasto (gramalote), hule, cedros, guayabillos, anonos, bananos y bambúes.

El río está limitado de cada lado por colinas bajas, cubiertas de cañaverales, gramalotes y platanillos o bijagua en primer término, sobre las playas, y más arriba por espesos bosques donde observé frondosos y elevadísimos árboles de balsa, guarumos, plomos, jiñotes, palmeras maquengues [maquenques], palma digitada, pejivalles [pejibayes], pacayas, palma real, ceibos, palo de la vaca, chilamates, almendros, jobos, anonos, patastes, caroños, helechos arborescentes, tabacones, guayabillos, plátanos occidentales, sangre-drago, caobas, grados, árbol de pascua, bambúes, cedros dulces, acacia arborescentes, gavilanes, piperáceas, campaña, ratón, danto, cedro colorado, ronrón, melón, cortés, laurel, camíbar, lagartillo, capulín, venado, mangle dulce, sotacaballos, copey etc., etc.

En el río abundan varias clases de buenos peces, entre otros, los guapotes, sábalos, robalos, barbudos, bagres, sardinas,

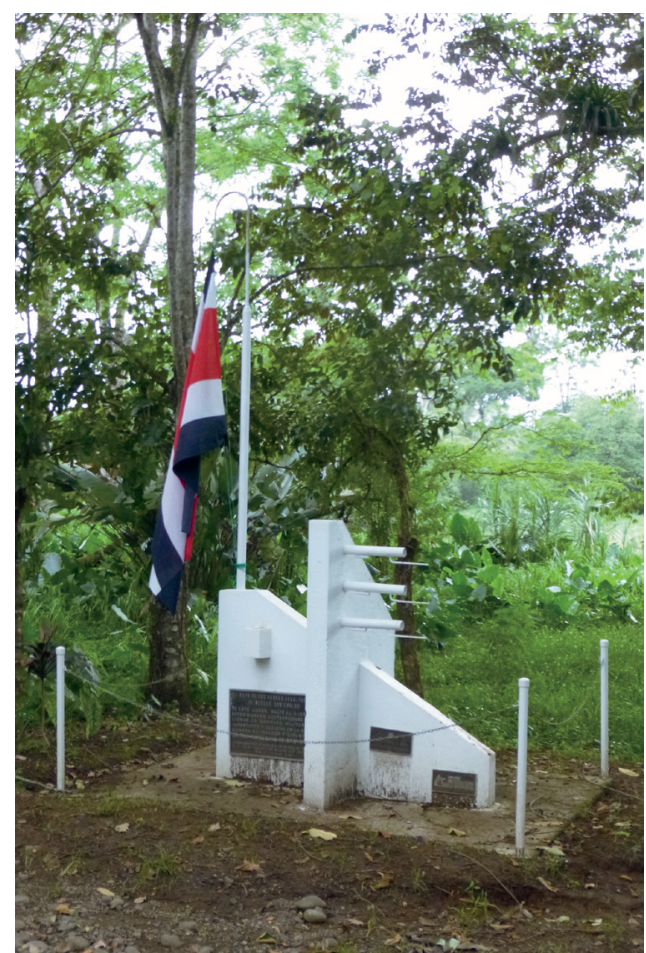
bobos, dormilonas, uluminas [olominas], roncadores, palometas y viejas.

En las selvas que bordean el río se solazan diversas clases de aves y pájaros de melodioso y variado canto. Hay abundancia de lapas de dos clases, loros, pericos, oropéndolas (2 clases), tucanos, palomas de montaña, perdices, codornices, sargentos, garzas (4 clases), patos, piches, ajoquines, cigüeñas, chorchas, martines, sucurrás; entre los mamíferos se encuentran la danta, el león-puma, el tigre, manigordo, tigrillo, oso colmenero, tepescuintle [tepezcuintle], tejón, perico-ligero, ardillas, nutrias, culumecas, y no escasa variedad de reptiles, algunos muy venenosos, como la toboba, la víbora negra, el coral, el cascabel, el tamagás, etc.

El río lleva una rápida pendiente hacia el San Juan, existiendo una diferencia de nivel sobre el mar y el resguardo de San Rafael de 180 pies $^{26}$; esto da a la corriente del río una velocidad media de tres millas por hora; su profundidad media es de dos pies de agua; en los remansos alcanza hasta cuatro y cinco varas, y en el invierno aumenta su caudal de aguas de una manera considerable, debido al gran número de ríos que recibe de las partes altas de las montañas o cordilleras del centro de la provincia de Alajuela.

Por el cómputo hecho, calculo el largo del río en 16 leguas $r$ [reales] y 3/4 de milla, en vez de las 15 leguas que le asigna la geografía nacional27. En todo el curso de San Carlos se cuenta 148 tablazos. Llaman así grandes extensiones de agua de 600 o 1200 varas y más, en forma de remansos a grandes curvas y de notable profundidad.

En la doble desembocadura del San Carlos en el San Juan (Figura 8), hallé dividida la región de los bosques en dos zonas longitudinales, una que se dirige hacia del río Toro Amarillo y Sarapiquí, y otra hacia el río Poco Sol [Pocosol] y territorio de los guatusos, zona que no me fue posible visitar por lo avanzado del invierno y el gran número de ríos poco vadeables ya en la estación lluviosa ${ }^{28}$.
Figura $7 C$ Hito histórico en Muelle. 


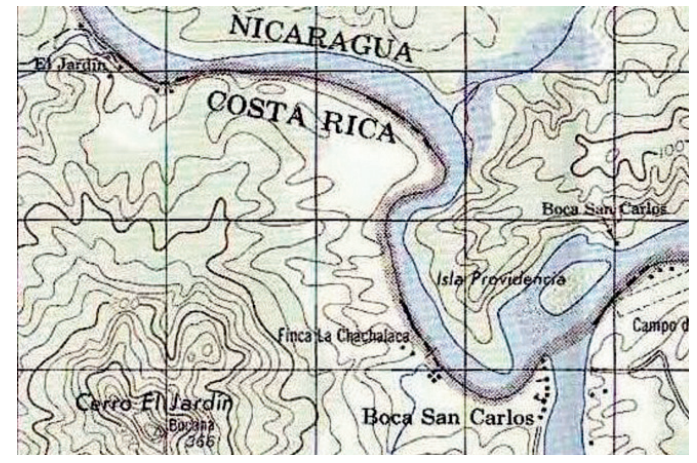

Figura 8A. Bifurcación aparente en la desembocadura del río San Carlos.

Figura 8B. Vista de la isla Providencia desde la margen derecha del río San Juan.
Del resguardo de San Rafael hacia el perímetro que ocupan las haciendas ya citadas, hay extensos y hermosos bosques donde he visto en todo su desarrollo el camíbar, el hule y el curioso árbol descubierto por Humboldt, en Venezuela, el palo de la vaca, que produce una leche azucarada parecida a la leche de vaca, y de la que hacía uso aquel sabio en el café y en el chocolate ${ }^{29}$; hay además gran número de plantas medicinales y preciosas maderas que se están cortando para nuestro Concurso [Exposición de Chicago].

En las fincas de estas llanuras, contiguas a los ríos San Rafael, Peje y Platanar, se da perfectamente el café de Liberia y el común, el cacao, gigantescos ñames de hasta 106 libras de peso, yucas enormes, camotes de 6 y 7 libras, cañas de azúcar del grosor de 11 pulgadas por 5 y 6 varas de $\operatorname{largo}{ }^{30}$, tiquisques [tiquizques], frijoles de varias clases, jengibre, sagú, bananos, arroz, vainilla, pimienta de Jamaica, árbol de pan [fruta de pan], cocos, resina copal, bálsamo camíbar, variados pastos, toda clase de palmeras, resina caraño [caraña], toda clase de legumbres, gomas de muchas clases, plantas de tinte, zarzaparrilla, simarruba [simarruda], cuasía [cuasia] amarga, fibras textiles, algodones de ceiba, balsa y barrigona [barrigón], aceites vegetales, jocotillo (muestra odorífera que traje al Sr. Presidente), y excelentes frutas; hechos tangibles y no vanas disertaciones, que colocan a esta comarca en primera línea entre todas las de la República.

El clima de la zona fluvial es templado y las continuadas lluvias refrescan el ambiente saturado de aromas y velado por densa niebla. El gran valle de San Carlos puede contener unos 400,000 acres de feraces y vírgenes tierras, y el día que el río del mismo nombre sea recorrido por un vaporcito de río, todos estos valiosos productos tendrán fácil salida hacia el río San Juan, San Juan del Norte y la América Sajona. La tierra es vegetal y el humus a veces tiene uno y dos pies de profundidad, sin piedra ni cascajo, y no es extraño que el crecimiento vegetal alcance en los árboles, tales como el plátano, 48 pulgadas en 42 días, no existiendo en todos estos valles la estación seca, y de doce meses llueve un poco más de diez en el año.

El clima de la zona próxima a los cerros de La Vieja es más fresco y es en donde existen los pastos naturales más extensos destinados a la cría de ganado, calculándose hoy éstos en unas 12.000 reses distribuidas en unas 18 haciendas. El cacao de la hacienda de Murillo es superior a cualquier otro de Centro América, y los árboles se ven agobiados bajo el peso de su valiosa carga ${ }^{31}$. 
Cuando desde las alturas de la cuesta de La Vieja se divisan estos extensos campos, que van a morir sobre las lejanas riberas del San Juan ${ }^{32}$, estas verdes campiñas llenas de vida y de colorido, salpicadas con bosque de palmas y helechos de todas clases; estos collados y cañadas siempre verdes y surcados por mil corrientes de cristalinas aguas, se siente uno transportado a esas regiones maravillosas del Amazonas, prototipo del génesis, que son la admiración del viajero y la gloria y riqueza de nuestra América.

A todo este cuadro veraz de una región que, andando el tiempo, puede ser el verdadero 'Dorado' de Costa Rica, debe agregarse la posición estratégica de esta comarca, en la confluencia de los derroteros del comercio, tales como son la obra de la nueva línea de ferrocarril que comunicará el interior del país, partiendo del puerto Limón y cortando el río San Carlos, cerca de la desembocadura del Tres Amigos, para dirigirse hacia río Frío; y por otro lado la grande empresa del Canal de Nicaragua, una de cuyas principales exclusas se asegura quedará situada muy cerca de la desembocadura del San Carlos en el San Juan ${ }^{33}$. Allí, no cabe duda, se creará entonces un centro de actividad comercial, una interesante población que tendrá fáciles comunicaciones por agua y por tierra con la zona descrita, proporcionando a los agricultores y hacendados de San Carlos las facilidades para la exportación de productos hacia los grandes mercados americanos.

Y vías de comunicación por tierra, hacia el centro de la provincia de Alajuela, es lo que le falta a San Carlos para desarrollar todos esos elementos de prosperidad, pues hoy todo se transporta a lomo de mula o por carretas, y a precios bastante elevados para que el café, el cacao, el caucho, la mantequilla, el queso, legumbres, frutas y granos no dejen sino poca utilidad a sus dueños.

Y si el terreno es fértil y barato, y la tierra reviste espléndidas galas y los pastos y frutos abundan, y el clima es sano, y las vías de comunicación son objeto ya de mediado estudio de parte del Gobierno, el día no está lejano en que una oleada de buena inmigración, venida acaso de la gran feria [Exposición] de Chicago, al conocer los exuberantes productos de San Carlos, se arroje sobre estos felices campos para darles todo el desarrollo que la industria y la ciencia agrícola invienen en el curso del progreso actual.

Allí cerca, en el Zarcero y Buenavista, el clima es benigno, delicioso, más fresco que en San José ${ }^{34} ;$ allí el francés, el vasco, el suizo o el alemán verán de nuevo con alegría el ciruelo, el durazno, la uva, la pera, la grosella y el membrillo, frutos de su país natal, al lado de nuestras esbeltas palmeras, del donoso banano, del lactecente [latescente] aguacate, de las aromáticas y dulces piñas y anonas.

¡El aspecto de esta región les recordará sus campiñas, sus montañas, aunque sin el excelso penacho de fuego de las nuestras; su sol brillante y su luna melancólica, aquí más espléndidos y majestuosos; la idea de la patria y de la familia, bajo todas las latitudes, estará siempre a su vista con auroras de rosicler y sus crepúsculos de oro, dando poderoso aliento a las reminiscencias gratas del hogar que parecen revivir más fecundas e imperecederas en estos cuadros grandiosos de nuestra americana naturaleza; y hasta los vaporcitos y frágiles barcas, que en el río desplieguen sus blancas velas a la luz del alba, parecerán mensajeros enviados para traerles de los lejanos hogares la esperanza de la familia y la paz del corazón; y en tanto que las mieses avanzan, que el hogar se ensancha, que el bienestar y la riqueza aumentan el haber del colono para volver a sus queridos lares, esta tierra generosa les brinda seguro asilo, les tiende una mano bienhechora y les da el abrazo del hermano, acaso para perpetuar en este suelo la prosperidad del capital y la santa idea de una sola familia y de una sola patria! 
Se han obtenido de esta región explorada un gran número de productos en vía hacia esta capital; 119 fotografías de las mejores perspectivas del valle y del río, que con las 172 del Guanacaste forman ya una colección de 291 fotografías ${ }^{35}$.

En los cantones de San Ramón, San Mateo, Atenas, Naranjo y Grecia se han nombrado agentes habilitados con fondos suficientes para la compra de objetos encargados $^{36}$. No dudo que esta región sea la mejor representada, en cuanto a productos vegetales. En las dos exploraciones, las distancias recorridas alcanzan a 579 millas. Se han traído curiosas muestras de la leche del palo de la vaca, de camíbar, de bálsamo negro, de gutaperchas, zarzaparrilla, cuasia, etc., y sobre todo una pieza de primera importancia, como espécimen de la fauna fósil del país, una gran muela de mastodonte, petrificada y en el mejor estado de conservación e integridad, que pesa muy cerca de 40 libras $^{37}$.

Esperando del señor Ministro, se sirva dar cuenta al señor Presidente de la República con el presente informe, tengo la honra de suscribirme su muy atento seguro servidor". (Guzmán, 1892, pp. 1 y ss.).

\section{Comentarios}

Antes de emitir algunos juicios acerca del contenido del informe de Guzmán, es pertinente señalar que para entonces había notables avances en el conocimiento botánico y zoológico en Costa Rica, gracias sobre todo a la labor de varios naturalistas que hicieron breves exploraciones o que residieron aquí. En orden cronológico, ellos fueron Emanuel von Friedrichsthal, Anders S. Oersted, Josef von Warszewicz, Hermann Wendland, Karl Hoffmann, Alexander von Frantzius, Julián Carmiol, Auguste Endrés, Helmuth Polakowsky, Otto Kuntze, Henri Pittier, Adolphe Tonduz, Paul Biolley, José Cástulo Zeledón y Anastasio Alfaro (Hilje, 2013); cabe acotar que, para la fecha del viaje de Guzmán, faltaban dos años para que el joven José Fidel Tristán empezara a realizar sus aportes científicos.

Ahora bien, se puede afirmar con certeza que fue Endrés el primer naturalista que incursionó en la región de San Carlos, entre 1867 y 1868, donde recolectó numerosos especímenes de orquídeas y colibríes, que eran sus grupos de su interés (Ossenbach et al., 2013). Lo sucedió Carmiol, quien en una ocasión permaneció recolectando animales y plantas por tres semanas, en 1868 (Hilje, 2013). Por un tiempo prolongado ningún otro visitó la región, con excepción del zoólogo Biolley, en 1886 y quizás alguna vez más. Posteriormente, a raíz de la iniciativa binacional para delimitar la frontera entre Costa Rica y Nicaragua, en junio de 1890, una comitiva encabezada por el ingeniero Luis Matamoros Sandoval viajó por el río San Carlos, para desplazarse por varias semanas hacia San Juan del Norte (Nicaragua) primero y bahía Salinas (Guanacaste) después; en ella figuraban Pittier y Tonduz como botánicos, y Alfaro como zoólogo y agrimensor.

Obviamente, todo esto debía haber hecho posible la identificación del material recolectado y preparado por Guzmán. Sin embargo, en el catálogo, él consigna el nombre científico de la mayor parte de las especies vegetales, pero no de las muestras (tablitas) de maderas aptas para construcción o ebanistería, y especifica, en una nota al pie, que "las maderas van con sus nombres nacionales. Muchas son desconocidas en Europa, y aún aquí, y su clasificación científica es obra de varios años" (Guzmán, 1892a). Esto es muy curioso, pues de seguro muchas o varias de ellas eran conocidas por Pittier y Tonduz, pero sugiere que Guzmán efectuó su tarea de manera aislada; en abono a esta hipótesis, llama la atención que en todo 
el catálogo no dé los créditos pertinentes a los expertos que pudieron haberle ayudado en la identificación de los especímenes vegetales o animales.

Cabe acotar que, para la región de San Carlos, su registro incluye 187 especies de plantas, clasificadas así según su utilidad: ornamentales (88), construcción o ebanistería (40), medicinales (23), textiles (13), tintóreas (11), gomas y resinas (9), alimenticias (3) y oleaginosas (3). Conviene aclarar que una misma especie puede tener más de un uso.

Aunque la inclusión de nombres científicos confiere un notable valor a su información, a diferencia de importantes eventos en los que Costa Rica participó antes, como la Exhibición Universal de Londres, en 1862 y la Exposición Internacional de Chile en 1875 (Hilje, 2013), hoy muchos de esos nombres son anacrónicos, en tanto que varios están mal escritos en el catálogo y otros corresponden a especies que no son nativas de Costa Rica, como se verá posteriormente. En todo caso, por su importancia histórica y biológica - a pesar de sus numerosos errores-, a continuación se anotan los nombres científicos vigentes de las especies de plantas provenientes de San Carlos, ya sea aludidas en su informe —en el cual Guzmán no menciona ningún nombre-, o en el catálogo, según su uso ${ }^{38}$.

De las especies para construcción o ebanistería, los únicos nombres con los que se tiene mayor grado de certeza son los siguientes: tanto el caimito amarillo como el colorado deben ser Chrysophyllum spp.; el corteza gruesa, Tabebuia guayacan; la cuajiniquil peluda, Inga sp.; el guapinol, Hymenaea courbaril; el jorcó o jorco, Garcinia madruno; el lagarto amarillo, Zanthoxyllum ekmanii; el lagarto negro, Zanthoxyllum panamense; el papayo almendro o almendro papayo, Dipteryx panamensis; el plomillo, Vitex cooperi, también conocido como manú plátano; el tamarindo silvestre, Dialium guianense; y la uruca, Trichilia havanensis u otra congénere.

En cuanto a nombres con algún grado de incertidumbre, el aya blanco y el colorado podrían pertenecer a la familia Lauraceae (quizás Ocotea sp. o Nectandra sp.), al igual que los iras blanco y caballo, en tanto que el quizarracillo podría ser una congénere, o Licaria sp.; el cacique y el cacique amarillo quizás sean Psidium spp. o Eugenia spp.; el canelillo tal vez es más bien el candelillo (Senna sp.); aunque se conoce como cascuá a Cupania glabra, esta especie no crece en zonas bajas; el cedro colorado podría corresponder a la caobilla o cedro macho (Carapa guianensis) o a Guarea spp., varias de las cuales son árboles grandes y maderables; el gallinazo, quizás Stryphnodendron microstachyum y no Schizolobium pararahyba, que es del Pacífico; el granadillo barcino podría ser el granadillo, Dalbergia glomerata; el madroño blanco, quizás Guettarda sp.; y el murta negro, tal vez Eugenia sp.

Hay mayores dudas con los siguientes nombres. El roble encina, Quercus sp., crece a alturas superiores a $1300 \mathrm{~m}$; la jamaica (Pimenta guatemalensis) crece ahí, pero más bien en la falda de las cordilleras, en tanto que el matasano (Cassimiroa edulis) no crece en San Carlos, mientras que el naranjillo o naranjito (Swartzia simplex), no es de la zona; el níspero blanco podría corresponder a Pouteria sp. o a Manilkara sp., pero estos árboles son raros ahí; y el nombre molenillo pastora es extraño, aunque a Quararibea asterolepis le llaman molenillo o guácimo molenillo, al igual que a otras congéneres.

Finalmente, no fue posible determinar los nombres científicos de las especies denominadas árbol colorado, conchudo ocotillo, ramal, siva y venado.

Ahora bien, de las especies que aportan tintes o pigmentos, son desconocidos los nombres científicos del culebro y el hibita; tanto el achiote colorado como el amarillo son variedades de Bixa orellana, como lo aclara Guzmán en el apéndice de su catálogo; el ratoncillo debe ser Myrsine coriacea; el ojo de venado (Mucuna muttissiana) podría corresponder a Mucuna urens, también conocido como ojo de buey, aunque en el citado apéndice figuran los nombres ojo de venado u ojo de buey 
como Mucuna pruriens; el nancite o nance, consignado como Malpighia punicifolia, debe ser Byrsonima crassifolia; tanto el sangre de toro (Machacaerium humboldtiana) como el sangre de drago (Pterocarpus draco) podrían pertenecer más bien a Pterocarpus hayesii, $P$. officinalis o $P$. michelianus, conocidos como sangregados y sangrillos; y la yuquilla o camotillo (Curcuma tinctoria) es la cúrcuma (Curcuma longa), originaria de Asia.

Para continuar con otras especies, de aquellas que aportan gomas y resinas se desconocen los nombres del Iliguaitil o goma azúcar, el sardinillo amarillo y el ocote de montaña; la resina copal (Hymenaea verrucosa) es propia de África; el hule es Castilla elastica; el copal es Protium sp.; la ceiba (Bombax ceiba) es más bien Ceiba pentandra; el ojoche macho debe ser Brosimum alicastrum, y el ojoche colorado algún congénere suyo; y el bálsamo podría ser Dalbergia glomerata.

De las pocas especies con valor alimenticio, el ñame (Dioscorea alata) es de origen asiático, pero traído aquí desde temprano en nuestra historia. Por su parte, el palmito derivado de la palma real (Oreodoxia regia) quizá más bien proviene de la palmilera (Iriartea deltoidea), el palmito (Euterpe precatoria) o el maquenque (Socratea exorrhiza); curiosamente, en el apéndice ya citado Guzmán alude de manera tangencial al cogollo o palmito de la palma real, y deja entrever su valor alimenticio para el ganado y las aves de corral. Por último, se desconoce qué es lo que él llama almidón de selva.

De interés especial es el palo de la vaca o árbol de la leche, pues su situación es algo enigmática en relación con su distribución en Costa Rica. Tanto sorprendió este a Humboldt, durante su recorrido por Venezuela, a fines del siglo XVIII, debido a su copiosa savia de valor alimenticio (Humboldt, 2005), que lo recolectó y envió a identificar.

Aunque en su catálogo Guzmán lo consigna como Brosimum galactodendrum, nombre hoy inexistente, en el respectivo apéndice menciona que originalmente fue bautizado como Galactodendrum utile, que es un sinónimo de Brosimum utile. Esto permitió rastrear su trayectoria taxonómica y detectar que en la actualidad se trata de Brosimum utile, conocido como mastate, al cual Pittier (1908) se refiere como "el árbol de la leche de Humboldt y común en la tierra caliente del Atlántico, subiendo hasta las selvas de nubes". No obstante, esta especie, también conocida en nuestro país como vaco o lechoso, no está en San Carlos, pues es propia de los bosques de la costa Pacífica; es curioso que sí aparezca en la región Atlántica de Panamá, Colombia, Venezuela y Brasil, mientras que en países sin contacto con el Atlántico - como Perú y Bolivia—, se halla en la cuenca del río Amazonas, que vierte sus aguas a dicho océano.

Todo esto indica que hay una equivocación. Pittier escribió su libro pocos años después de abandonar Costa Rica, cuando residía en Washington, y aún no vivía Venezuela, adonde llegaría en 1913. Es decir, su afirmación quizás se basó en el informe de Guzmán, aunque no lo menciona en la bibliografía de su libro, lo que hace pensar que quizás se dejó influir por algún viejo comentario que le hiciera Guzmán.

Por tanto, es posible que Guzmán confundiera la citada especie con alguna parecida. En tal sentido, dos especies que producen abundante látex y crecen en la región caribeña son el mastate (Poulsenia armata, familia Moraceae) y el palo de la leche (Couma macrocarpa, familia Apocynaceae). Aunque ambas difieren de aquéIla en varios aspectos evidentes de la morfología de las hojas, las ramas o el tronco, cabe recordar que Guzmán sabía muy poco de botánica, como para diferenciarlas ${ }^{39}$.

En cuanto a especies de importancia textil, él menciona con exactitud la balsa (Ochroma lagopus) y el anono o anona (Annona reticulata), pero se equivoca con nombres como el burío (Heliocarpus appendiculatus y no Bombax apeiba), la cabuya (Furcraea cabuya y no Agave tuberosa) y el mastate (Brosimum utile y no Castilla elastica). De las demás, no cita sus nombres, pero el corteza blanca podría ser el 
roble de sabana (Tabebuia rosea); la chirravaca podría corresponder a la chidra o chirrabaca (Carludovica palmata); el palanco, diferente de Sapranthus palanga, propio del Pacífico, podría ser Rollinia sp. o Guatteria sp.; un bejuco anotado como hombre grande no es Quassia amara, sino más bien alguna especie de Smilax, pariente de la zarzaparrilla; y, por último, se ignora lo que son el chol y la cucanilla.

En relación con especies aptas para tenería o curtiembre, tan solo menciona dos. El nombre del gavilán (Mimosa arborea) más bien podría corresponder a Pentaclethra macroloba, y el del guanacaste amarillo (Enterolobium sp.) al guanacaste que crece en San Carlos, denominado Enterolobium schomburgkii.

Ahora bien, en el caso de las palmas, en su catálogo aparecen 25 especies de palmas y dos de palmiches, todas con sus nombres científicos; si bien Guzmán anota que son de valor ornamental, varias también son fuentes de fibras, alimentos, etc. No obstante, hay muy serios problemas taxonómicos o de nomenclatura, según el experto Michael Grayum, referidos a continuación.

Por ejemplo, Guzmán enlista y consigna como palmera jipijapa una especie que clasifica como Carludovica cyclanthus, que es un nombre inexistente, pues tanto Carludovica como Cyclanthus corresponden a géneros diferentes; además, las Arecaceae (palmas) son una familia diferente de las Cyclanthaceae. Aunque inicialmente pudiera pensarse que se refiriera a la chidra o estococa (Carludovica palmata) - con la que se confeccionan los elegantes sombreros de jipijapa-, presente en San Carlos, quizás más bien aludía a Cyclanthus bipartitus, también frecuente en San Carlos; no obstante, en el apéndice de su catálogo sí menciona a C. palmata, pero con el nombre de junco o palma de sombreros.

Por su parte, la palma real citada por Guzmán como Oreodoxa regia es Roystonea regia, pero es propia de algunas áreas del Caribe, que no incluyen a Costa Rica, de modo que no es una especie nativa, sino exótica. En el citado apéndice alude a ella, pero de manera confusa y termina comparándola en majestuosidad con el maquenque. Ahí mismo asigna el nombre de palmito a la palmera enana (Chamaerops humilis), que es europea y de aspecto totalmente distinto. Erra también en el catálogo, donde menciona como nativas a la palmera datilera (Phoenix dactylifera) y dos congéneres que son propias de África o Asia; de estas, la que él denomina palmera danta (Phoenix acaulta) es más bien una palmera datilera enana (Phoenix acaulis), en tanto que Phoenix tenuifolia es un nombre inexistente.

También es inexistente el nombre Bactris reptans, con el que Guzmán identifica a la que él llama palmera trepadora, pero es casi seguro que se refiere a Desmoncus moorei, que es la única especie de palma trepadora en San Carlos, espinosa y muy relacionada con el género Bactris. La que él denomina palmera danto-espino (Bactris fusca) corresponde hoy a Bactris glandulosa. La palmera biscoyol (Bactris horrida) es el biscoyol o huizcoyol (Bactris guineensis). Las tres especies tienen algún grado de cercanía taxonómica con el pejibaye (Bactris gasipaes), conocido en aquel entonces como pejivalle (Guilielma utilis).

La palma de coyol, anotada como Olercaceae vinifera, está mal consignada, pues ese nombre genérico no ha existido nunca y podría corresponder más bien a la familia Olacaceae, que no tiene relación alguna con palmeras. Cabe suponer que se trataba de Acrocomia aculeata (= Acrocomia vinifera), cuyo epíteto alude a un conocido vino o fermento que se extrae de él, pero es propia del Pacífico, por lo que no crece en San Carlos; curiosamente, en el apéndice de su catálogo Guzmán aporta alguna información sobre el coyol, que consigna como A. vinifera, pero sin mencionar su distribución en Costa Rica. Asimismo, el corozo, que él clasifica como Attalea cohune, más bien podría ser Attalea butyracea, también llamada palma real.

La denominada palmera-palmito (Astrocaryum vulgare) es endémica de Brasil, de modo que más bien podría tratarse de Astrocaryum alatum, frecuente en San 
Carlos; aunque es una palma muy espinosa, difícil de confundir con representantes de Euterpe o Iriartea, la alusión en el nombre común a su apetecible cogollo sugiere alguna confusión con el palmito (Euterpe precatoria) o el palmito dulce o palmilera (Iriartea deltoidea). Por su parte, el palmiche común aparece consignado como Elaeis melanococca, que es un sinónimo de Elaeis guineensis, correspondiente a la palma aceitera, originaria de África; podría tratarse más bien de Elaeis oleifera, nativa de Costa Rica y presente en San Carlos.

Para agregar confusión a la lista de Guzmán, el nombre correcto de la llamada palmera ventanilla no es Euterpe Iongipulata, sino Euterpe longepetiolata, hoy llamada Prestoea longepetiolata, pero no crece en San Carlos. El nombre del palmiche morado (Enocarpus utilis) es Oenocarpus utilis, que es un sinónimo de Prestoea acuminata, conocido como palmito morado o chonta, pero tampoco crece ahí, como sí lo hace su congénere Prestoea decurrens.

La palmera blanca (Geonoma undata) podría corresponder a Geonoma edulis, pero no crece en San Carlos. Además, aunque Guzmán cita la súrtuba como Geonoma simplifrons, cuyo nombre correcto es Geonoma simplicifrons (sinónimo de Asterogyne martiana), y es muy frecuente en San Carlos, esta especie no es la verdadera súrtuba (Geonoma interrupta), de valor alimenticio por su amargo pero gustado cogollo. Asimismo, la palmera maquengue, que él clasifica de manera impropia como Copernicia tectorum, que es una especie de los llanos de Venezuela y Colombia, más bien corresponde a alguna especie de Cryosophila; hoy se denomina maquenque, y no maquengue, a Socratea exorrhiza y a Oenocarpus mapora. En realidad, según el experto Grayum, nombres como súrtuba y maquenque se utilizan con muy poco criterio técnico en Costa Rica.

En cuanto a la cola de gallo, que cita como Areca alicaea y cuyo nombre correcto es Areca aliceae (hoy Areca triandra), es originaria de Asia; quizás más bien corresponde a la cola de gallo o suita (Calyptrogyne ghiesbreghtiana), cuyo follaje es utilizado para techar ranchos. Aunque Guzmán menciona la palmera-suitá (Chrysalidocarpus luteaescens), este último nombre científico, cambiado hoy por Dypsis lutescens, corresponde a una pequeña palmera ornamental denominada palma múltiple, originaria de Madagascar. En relación con la pacaya, la cita de manera equivocada como Kumtia montana, cuando lo correcto es Kunthia montana; pero, en todo caso, esta especie no está en Costa Rica, y quizás corresponde a Chamaedorea costaricana u otra congénere.

La palmera de abanico, citada como Ltystonia olfvieformis, que es un nombre mal escrito, se llama Livistona chinensis y es nativa de la China. Asimismo, la palmera de escoba no corresponde a Chamaerops fortunei (hoy Trachycarpus fortunei), endémica de la China, sino tal vez a Colpothrinax aphanopetala, hoy bastante escasa en Costa Rica; aunque hay una especie llamada palmera de escoba o guágara (Cryosophila warscewiczii), por el color de sus fibras es menos parecida a T. fortunei. Por su parte, la palmera de Bengala (Calamus rotang), originaria de Asia, corresponde al ratán, con cuyas fibras, parecidas al mimbre, se elaboran muebles y artesanías. Además, la palmera de hierro (Dycthyosperma rubrum), conocida más bien como palmera princesa o palmera huracán y denominada Dictyosperma album, es propia de las islas Mascareñas, en el océano Índico. Por último, la palmera-espino (Caryota urens), cuyas hojas son urticantes, es nativa de la India y Malasia.

En síntesis, en este listado de palmas y especies afines se percibe que abundaron las identificaciones incorrectas, basadas en especies inexistentes en Costa Rica. En otros casos, pareciera que ya había en el país algunas especies exóticas, pero lo cierto es que Guzmán debió haber tenido el cuidado de no incluirlas como representativas de nuestra flora, en una exposición cuyo objetivo era mostrar especies y productos autóctonos de cada país. 
Ahora bien, en relación con los helechos, la situación no difiere mucho. Guzmán enlista nueve especies, sobre las cuales hay serias dudas. Por ejemplo, el helecho de pozo (Adiantum capillus veneris) es una especie europea, inexistente en Costa Rica, en tanto que el helecho durazno (Adiantum macrophyllum) también es exótico. Asimismo, el helecho común (Pteris aquilina) quizá se refiere a Pteridium aquilinum, que en el pasado incluía un complejo de especies y ahora es un nombre reservado para una especie europea; las únicas especies que existen en Costa Rica son $P$. arachnoideum y $P$. caudatum.

Con el nombre "helecho lengua de ciervo" (Scolopendra officinalis) posiblemente alude a Scolopendrium officinale, pero no está en Costa Rica; más bien podría corresponder a Campyloneurum phyllitidis o C. latum, a Nihidium crassifolium o $N$. oblanceolatum, o incluso a alguna especie de Elaphoglossum. Por su parte, el nombre de la especie consignado para el helecho penachudo (Aspidium paniculatum) no existe en la literatura botánica; eso sí, el nombre del género Aspidium se aplicó a especies hoy comprendidas en géneros como Thelypteris, Ctenitis, Megalastrum y Dryopteris. En cuanto al género del citado helecho arbóreo (Aisophyla proinata), es más bien Alsophila y la especie podría corresponder a $A$. cuspidata, presente en zonas bajas; por su parte, el helecho gigante (Alsophila gigantea) pareciera ser $A$. erinacea, que es la especie más grande de dicho género en Costa Rica.

Finalmente, el helecho hembra (Aspidium filix foemina) probablemente se refiera a Athyrium felix-femina, ausente en Costa Rica, donde sí existen sus congéneres $A$. caudatum y $A$. dombei. En relación con el helecho macho (Nephrodium filis-mas), podría corresponder a Dryopteris filix-mas, pero no está en Costa Rica. El Ilamado helecho festonado (Asplenium abscissum) sí es correcto, y es una especie presente en los bosques húmedos del país, casi siempre en altitudes mayores a los $600 \mathrm{~m}$.

En cuanto a otras plantas ornamentales, hay varios nombres comunes o científicos hoy inexistentes, aunque el nombre genérico sí esté vigente. Este es el caso del aro común (Arum vulgare) y aro baleado (Arum incisa), guaco morado (Aristolochia anguicida), platanillo blanco (Thalia variegata) y platanillo morado (Thalia rubrum). Asimismo, Guzmán consigna tres especies congéneres, que identifica como bijagua (Canna maranta), bijagua flor erecta (Canna flore erecta) y bijagua flor péndula (Canna luteola rubra), una o más de las cuales posiblemente correspondan a Calathea crotalifera o a C. lutea.

En relación con los nombres científicos correctos -y vigentes hoy-, figuran el achiote colorado y el achiote amarillo (ambas Bixa orellana), almendro (Terminalia catappa), copey (Clusia rosea), flor de pascua o campanilla morada (Ipomoea purpurea), guaco blanco o bejuco de guaco (Mikania guaco), hombre grande (Quassia amara), lirio de montaña (Crinum erubescens) y pita floja (Fourcroya gigantea).

Otros nombres han cambiado, pero no todas son plantas nativas. Entre los que han variado figuran el árbol de pan (Artocarpus incisa), hoy Artocarpus altilis; camote (Convolvulus batata), hoy Ipomoea batatas; cordoncillo (Piper angustifolia), hoy Piper aduncum; itavo o itabo (Agapanthus grandiflora), hoy Yucca guatemalensis; piñuela (Bromelia pinuela), hoy Bromelia pinguin; pitahaya (Cereus pitajaya), hoy Hylocereus undatus; planta terciopelo (Canna rubra), quizás hoy Canna indica; poró (Erythrina corallodendron), hoy Erythrina costaricensis; sábila (Aloe vulgaris), hoy Aloe vera; saúco (Sambucus nigra), hoy Sambucus mexicana; tabaco común (Nicotiana rustica), hoy Nicotiana tabacum; yuquilla, camotillo o cúrcuma (Curcuma tinctoria), hoy Curcuma longa.

Cabe acotar que con el nombre "hule", Guzmán menciona tanto a Castilloa elastica, hoy Castilla elastica, como a Siphonia cahuchu, antiguo nombre de Hevea guianensis, especie suramericana que no crece en Costa Rica, al igual que sucede con el hule o caucho (Hevea brasiliensis), de gran valor comercial. 
Otros nombres son correctos, pero se trata de especies exóticas, como el alcaucil o alcachofa (Cynara scolymus), cardón de cerco (Euphorbia triangularis), ceibón (Eriodendron aufractuosum), euforbio o cactus moruno (Euphorbia officinarum) y ruibarbo exótico (Rheum rhaponticum). Lo es también la hoja de aire (Bryophylum calicinum), hoy Kalanchoe pinnata, el paraíso (Melia sempervirens), hoy Melia azedarach, y la saxifraga (Saxifraga granulata).

Finalmente, el chilamate (Ficus laurifolia) podría ser Ficus insipida, la floripondia (Datura suaveolens) es realmente la reina de la noche (Brugmansia suaveolens) y el lirio de árbol (Epidendrum sp.) es más bien una orquídea. Además, Ilama la atención el largo y complicado nombre de chaparro churvico bobo, que Guzmán identifica como Curatella americana, nombre del raspaguacal, pero no crece en el Caribe, sino en el Pacífico seco. Por su parte, menciona al cafeto enano y lo identifica como Coffea exigua, pero esta especie no existe, al igual que sucede con el trepa-palos (Philodendrum integrifolia), cuyo nombre genérico debiera ser Philodendron, pero esa especie nunca fue descrita. En relación con tres especies de magueyes, es correcto el nombre del maguey común (Agave americana), pero no es nativo de Costa Rica, en tanto que el maguey sin espina (Agave bromeliaeformis) corresponde a Agave bromeliaefolia; por su parte, el maguey orlado (Agave variegata) hoy se denomina Manfreda variegata.

En cuanto a especies no arbóreas, los platanillales corresponden a áreas densas de platanillo o bijagua, que con frecuencia crecen de manera profusa cerca de cuerpos de agua. Asimismo, aunque en algunos países suramericanos se le llama gramalote, en Costa Rica se conoce como gamalote a la gramínea Paspalum fasciculatum, que forma inmensas macollas. A la vainilla y la zarzaparrilla se aludió en páginas previas. Los bambúes citados podrían corresponder a Bambusa vulgaris, especie nativa del sureste de Asia, e importada y vendida ya en 1878 por el maestro-jardinero alemán Julián Carmiol en la capital, desde donde poco a poco se empezó a distribuir por otras zonas.

Los nombres de otras plantas de valor comercial, nativas o exóticas, son: café de Liberia (Coffea liberica), café común (Coffea arabica), cacao (Theobroma cacao), ñame (Dioscorea sp.), yuca (Manihot esculenta), camote (Ipomoea batatas), caña de azúcar (Saccharum officinarum), tiquizque (Xanthosoma sp.), frijol (Phaseolus sp.), jengibre (Zingiber officinale), sagú (Maranta arundinaceae), banano (Musa acuminata), plátano (Musa acuminata X M. balbisiana), arroz (Oryza sativa), fruta de pan (Artocarpus altilis), coco (Cocos nucifera), copal (Protium sp.), camíbar (Copaifera aromatica), caraña (quizás Protium sp.), simarruda o amargo (Aspidosperma spruceanum), cuasia (Quassia amara), ceiba (Ceiba pentandra), balsa (Ochroma pyramidale) y barrigón (Pseudobombax septenatum). El jocotillo, nombre inexistente hoy, pero que tampoco consigna Pittier (1908), podría ser el mismo jobo (Spondias mombin), congénere del jocote (Spondias purpurea).

Los nombres de otras especies de árboles son: guarumo (Cecropia insignis), plomo (quizás Vitex cooperi, también conocido como manú o plátano), jiñote o jiñocuabe (Bursera simaruba), maquenque (Socratea exorrhiza), pejibaye (Bactris gasipaes), pacaya (Chamaedorea sp.), ceibo (Ceiba pentandra), chilamate (Ficus sp.), almendro (Dipteryx panamensis), tabacón (Cespedesia macrophylla), guayabillo (tal vez Eugenia sp.), sangre-drago o sangrillo (Pterocarpus officinalis), caoba (Swietenia macrophylla), cedro dulce (Cedrela odorata), gavilán (Pentaclethra macroloba), piperáceas (Piper sp. y otras), danto o danto amarillo (Sideroxylon capiri), ronrón (Astronium graveolens), cortés (Tabebuia guayacan, también conocido como corteza o guayacán), laurel (Cordia alliodora), lagartillo (Zanthoxylum sp.), capulín (Trichospermum grewifolium), mangle dulce (Tovomita longifolia o Distovomita paniculata), sotacaballo (Zygia longifolia) y copey (Clusia sp.). 
Aparte de estos, Guzmán menciona nombres no usados hoy, como palma digitada, plátanos occidentales, acacia arborescente, grado, árbol de pascua y venado, lo cual impide su identificación.

Además, hay otras imprecisiones, como el caroño y la campana, que podrían ser más bien la caraña (quizás Protium sp.) y el campano (Saccoglottis trichogyna). El anono podría corresponder al anonillo (Guatteria sp., Unonopsis sp. o Rollinia sp.). El pataste (Theobroma bicolor) está en la zona, pero más bien podría tratarse del mastate (Poulsenia armata). Los helechos arborescentes (Cyathea spp.) no son comunes en zonas bajas; el ratón podría ser Myrsine sp., pero las dos especies que hay en el país crecen en alturas mayores. Aunque dos especies son conocidas como melón (Agonandra macrocarpa y Schoepfia schreberi), ninguna es propia de esta zona.

Como síntesis de lo referido a plantas, es evidente que son demasiados los errores en que incurrió Guzmán, lo cual debilita seriamente el valor científico de su informe. Al respecto, es curioso que al referirse a las muestras de maderas, prescindiera de sus nombres científicos, por no conocerse suficiente sobre ellas; de hecho, al pie del cuadro que enumera el material, él consigna que "las maderas van con sus nombres nacionales. Muchas son desconocidas en Europa, y aun aquí, y su clasificación científica es obra de varios años". Sin embargo, se aventuró a especificar los nombres de muchas otras plantas, presentes o ausentes de la región de San Carlos. Esto hace suponer que, carente de criterios sólidos - por no ser botánico-, lo que hizo fue utilizar libros u otras publicaciones extranjeras para efectuar identificaciones por aproximación, con base en dibujos o descripciones en prosa, con resultados bastante lamentables.

Ahora bien, en relación con la fauna de la región, se concentra exclusivamente en los animales vertebrados, quizás por ser los más perceptibles por a su tamaño, colores o comportamiento, por su utilidad, o por los peligros que representaban para la gente ${ }^{40}$.

En tal sentido, las especies de peces mencionadas corresponden al guapote $(\mathrm{Pa}-$ rachromis dovii), sábalo (Megalops atlanticus), robalo (Centropomus parallelus, posiblemente), barbudo (Rhamdia nicaraguensis, $R$. guatemalensis o $R$. rogersi), bagre (Ariopsis seemanni), sardina (Astyanax aeneus), bobo (Joturus pichardi), olominas o saltones (Rivulus isthmensis) y vieja (Tomocichla tuba). Por su parte, las dormilonas o dormilones son miembros de la familia Eleotridae, como las guavinas (Gobiomorus spp.), en tanto que las palometas podrían corresponder a Vieja maculicauda o a Oligoplites palometa; esta última es una especie perteneciente a la familia Carangidae que, aunque marina, puede migrar algunos kilómetros aguas arriba en los ríos.

En cuanto a los reptiles, los lagartos podrían ser el caimán o guajipal (Caiman crocodilus) o el cocodrilo (Crocodylus acutus).

Acerca de las serpientes, a la tamagá (Porthidium nasutum) terrestre a veces se le confunde con la bocaracá u oropel (Bothriechis schlegelii), que es arborícola. Con las demás hay mucha imprecisión. Por ejemplo, la cascabel (Crotalus durissus) es de zonas secas, por lo que más bien podría tratarse de la cascabel muda o matabuey (Lachesis stenophrys). El término víbora negra no se utiliza hoy, por lo que podría aludir a la zopilota (Clelia clelia), la mica (Spilotes pullatus) o la serpiente de látigo negra (Chironius grandisquamis). Asimismo, en esa zona no hay una, sino tres especies de corales venenosas: la coral gargantilla (Micrurus mipartitus), la coral del Caribe (Micrurus mosquitensis) y la coral gigante de agua (Micrurus alleni). Finalmente, el nombre "toboba" es más bien genérico, pues se utiliza para aludir a víboras que posean fosetas loreales, es decir, dos pequeñas cavidades en la cabeza con receptores de temperatura, que les permiten detectar a sus presas; es posible que Guzmán se refiriera a la terciopelo (Bothrops asper), que es muy común ahí. 
De las aves citadas, se trata de las guacamayas o lapas roja (Ara macao) y verde (Ara ambigua), loras (Amazona spp.), pericos (Brotogeris jugularis o Aratinga sp.), oropéndolas (Psarocolius montezuma y P. wagleri), tucanes (Ramphastos sulfuratus), palomas de montaña (Patagioenas sp.), perdices (Tinamus major o Cryptorelus soui), codornices (Odontophorus sp.), sargento (Agelaius phoeniceus), garzas (cuatro especies indeterminadas de la familia Ardeidae), patos (quizás Anas discors), piches (Dendrocygna autumnalis), ajoquines (Tigrisoma mexicanum), cigüeñas (Mycteria americana), chorcha (Icterus galbula o l. pustulatus), martines (familia Alcedinidae) y sucurrás; este último nombre no existe.

Por su parte, los mamíferos mencionados corresponden al venado cola blanca (Odocoileus virginianus), aunque también vive ahí el cabro de monte (Mazama americana). La culumeca es un nombre inexistente, que quizás corresponda al tolomuco (Eira barbara). Los demás son la danta (Tapirus bairdii), león o puma (Puma concolor), tigre o jaguar (Panthera onca), manigordo u ocelote (Leopardus pardalis), tigrillo o caucel (Leopardus tigrinus o L. wiedii), oso colmenero (Tamandua mexicana), tepezcuintle (Agouti paca), tejón o grisón (Galictis vittata), perica ligera u oso perezoso (Choloepus hoffmanni o Bradypus variegatus), ardillas (Sciurus granatensis o S. variegatoides), y nutria o perro de agua (Lontra longicaudis).

Finalmente, las especies más gustadas como carne de monte por los cazadores en esa región, aparte del venado cola blanca y de aves como las pavas (Penelope purpurascens u Ortalis cinereiceps), son el tepezcuintle, el cariblanco (Tayassu pecari) y el saíno (Pecari tajacu).

Es interesante mencionar que a la Exposición se enviaron pieles de 22 especies de mamíferos, provenientes de diferentes localidades de Costa Rica, algunos de cuyos nombres científicos son anacrónicos o incorrectos. Por su valor testimonial e informativo y, dado que algunas de estas especies viven en la región de San Carlos, sus nombres se enumeran a continuación.

Los únicos correctos - se mantiene aquí el nombre común de entonces-son los de la guatusa (Dasyprocta punctata) y el perico-ligero (Choloepus hoffmanni). Los demás, en el mismo orden en que aparecen en un párrafo previo, corresponden a: venado (Ciriacus virginianus), cabro montés (Cervus rufus), cholomuco (Galictis barbara), león o puma (Felis concolor), tigre (Felis onca), oso colmenero (Myrmecophaga jubata), tepescuintle (Dasyprocta maculata), ardilla negra (Sciurus nigra), ardilla colorada (Sciurus cinereus) y nutria negra o barcina (Ursus lotor), cerdo montés o zahino (Sus americanensis).

Otras pieles fueron las del mono congo (Mycetes palliatus), mono colorado (Ateles geofroyi), mono negro (Ateles comm), gato montés (Vulpes virginianus), erizo o puerco-espín (Coendu prehensilis), pizote (Nasua solitaria) y mico-león (Felis yaguarundi); no se mencionan los nombres científicos de la pantera negra, ni del tigrillo o caucel. De ellos, los nombres actuales son: mono congo (Alouatta palliata), mono araña (Ateles geoffroyi), zorra gris o tigrillo (Urocyon cinereoargenteus), puercoespín (Coendou mexicanus), pizote (Nasua narica) y león breñero o yaguarundi (Herpailurus yaguarondi). Es posible que el mono negro, cuyo nombre científico no existe, sea una variante del mono araña, al igual que lo es la pantera negra del jaguar (Panthera onca), en tanto que el tigrillo o caucel podría ser Leopardus tigrinus o L. wiedii.

Para concluir, a pesar de las numerosas deficiencias, sobre todo de carácter taxonómico, debe resaltarse que el informe de Guzmán encierra un gran valor en los campos de las ciencias agrícolas y naturales, pues representa el primer relato publicado en Costa Rica acerca del aprovechamiento real o potencial de las riquezas naturales de una región en particular. En tal sentido, constituye un modelo particular de trabajo exploratorio que, si se hubiera continuado - superadas sus falencias con el conocimiento 
taxonómico adquirido en años posteriores-, habría permitido contar con un inventario comprensivo y sólido de los recursos naturales del país, así como con un valioso testimonio de numerosos aspectos de la geografía humana que permitirían entender mejor los procesos de colonización de las zonas rurales del país.

\section{Notas}

1. Pariente algo lejano de Braulio Carrillo Colina -Jefe de Estado muerto en el exilio en 1845, era hijo de Rafael Fernández Alvarado y Joaquina Carrillo Valverde, según el genealogista Emilio Obando; fue bautizado en el Curato de San José el 23 de marzo de 1825.

2. Trazado en un papel-tela encerado de grandes dimensiones $(90 \times 180 \mathrm{~cm})$, se intitula Mapa del camino y río de San Carlos mandado levantar por la Compañía Empresaria (Mapas- 22184, Archivo Nacional de Costa Rica).

3. Los nombres científicos de las especies de animales y plantas citados en todo el texto, en relación con San Carlos, aparecen en la sección de Comentarios del presente artículo.

4. En cuanto a las unidades de medida citadas en el texto, corresponden a: legua $(5,57$ $\mathrm{km})$, milla $(1,6 \mathrm{~km})$, vara $(83,5 \mathrm{~cm})$, pie $(30,47 \mathrm{~cm})$, caballería $(45,25 \mathrm{ha})$, manzana $(0,7$ ha), acre $(0,4 \mathrm{ha})$ y libra $(460 \mathrm{~g})$.

5. Según Jorge Rolando Molina, la inmensa área denunciada por Fernández (16 516 ha) no le fue concedida por el Gobierno después, aunque él siempre tuvo considerables extensiones.

6. Boletín Oficial (31 de agosto de 1854, No. 36, p. 142).

7. Juzgado Contencioso Administrativo-4389 (28 de agosto de 1854, folios 1-2) (Archivo Nacional de Costa Rica). Al oeste hay una fila con tres cúspides, entre las que sobresale la de el San Carlos, hoy denominado cerro El Jardín, además de que al sureste aparecen los Cerritos Gemelos (Hoja cartográfica 121 Cutris, del Instituto Geográfico Nacional).

8. Este mapa porta la leyenda Mapa original de la parte norte de Costa Rica, según un dibujo original del Dr. A. v. Frantzius, utilizando otros materiales de A. Petermann. Data de 1861 y su escala es de 1: 1000 000, es decir, cada centímetro en el papel equivale a una distancia de un millón de centímetros $(10 \mathrm{~km})$ en el mundo real. Aunque el mapa circula zonto en la internet, Hilje (2013) demostró que se le desagregó de manera involuntaria del artículo Aportes al conocimiento de los volcanes de Costa Rica, que no lo contiene.

9. El río Cooper se llama Kopper en la actualidad, por razones que serán discutidas después.

10. Aclaración debida al especialista Guillermo Alvarado Induni. Él indica que algunos elementos añaden confusión. Por ejemplo, cerca del Platanar está el volcán Porvenir, igualmente dormido, y en la cumbre cratérica de ambos hay sitios pantanosos; además, en las faldas del Porvenir están las lagunas El Congo y Pozo Verde, y unos 3 km al sur de este, una finca conserva el nombre Lagunilla. En cuanto al Ilamado volcán Viejo, también conocido como Monte Cristo o Toro Amarillo en algunos mapas antiguos, es un cerro que forma parte de la fila La Chocosuela, un antiguo volcán extinto (el paleovolcán Chocosuela). 
11. En esta lista hay varios nombres incompletos o erróneos, como los de Ernesto Mellis, Luis Daser, Franz Kurtze, Conrad Runnebaum y Auguste R. Endrés. No fue posible hallar los nombres completos de Lacroix y Beyer.

12. Información aportada por el historiador Jorge Rolando Molina. Además, el sancarleño Fenelón Quesada (1958) recopiló muy valiosos testimonios acerca de las vicisitudes de los primeros pobladores del cantón de San Carlos, así como del ulterior desarrollo de esta rica zona (Quesada, 1958).

13. Toda la información aquí consignada sobre la citada exposición proviene de un amplio grupo de expedientes depositados en el Archivo Nacional de Costa Rica, y clasificados como Fomento-3929, 4239, 4240, 4241, 4246, 4484, 4540, 4576, 4577, 10309 y 11760.

14. Se les cita aquí como dos publicaciones independientes, dado que cada una tiene su propia paginación, así como un formato diferente. En cuanto a Orozco, en 1892 se le cancelaron 405 pesos por preparar nueve cajas de insectos, y a Pfau 314 pesos, sin que conste el motivo. No obstante, en el catálogo se especifica que Pfau aportó 350 especímenes de 57 especies de orquídeas, cuyos nombres científicos aparecen ahí; cabe indicar que ninguna provenía de San Carlos.

15. Hay abundante información sobre su vida y obra en Díaz (2005). Por cierto, la denominación del Museo Nacional de Antropología Dr. David J. Guzmán, en San Salvador, certifica la gratitud de sus paisanos, pues él fue el fundador y primer director de dicho ente.

16. Fomento- 4239 (18 de abril de 1892, folios 11-19). En otro expediente (Fomento- 10309) aparece una breve carta, fechada el 11 de abril de 1892, con datos complementarios.

17. Información aportada por el experto Quírico Jiménez.

18. Al parecer, en ese entonces era Joaquín Lizano Gutiérrez, quien en junio fue sustituido por José Vargas Montero.

19. Por cierto, Rafael fue mi bisabuelo. Una hija suya, Maclovia Rodríguez Rojas, se casó con Lupicio Quesada Quesada, hijo de José Joaquín Quesada Rodríguez y María de los Ángeles Quesada Ugalde; según Jorge Rolando Molina, el padre de Lupicio nació en Santa Gertrudis de Poás (hoy, de Grecia) y su madre en Palmares, tierra de donde partieron su padre y su tío José María para fundar la actual Ciudad Quesada.

20. La Gaceta (21 de mayo de 1892, No. 117).

21. El texto da la idea errónea de que se instaló algún tipo de ente gubernamental para recolectar materiales. En realidad, Koschny recolectó a título personal y de manera muy activa, lo cual se percibe en el hecho de que a los 200 pesos que Guzmán le entregó en mayo, se le sumarían 433.15 pesos en agosto.

22. Es evidente que se refiere a las cordillera conformada por los volcanes Platanar y Porvenir, más la fila La Chocosuela.

23. Dicho cerro aparece cerca de la desembocadura del río San Carlos, según el mapa de Friederichsen, ya citado; hoy se le denomina cerro El Jardín (hoja cartográfica $121 \mathrm{Cu}$ tris, del Instituto Geográfico Nacional). En efecto, en dicho mapa los ríos Arenal y Peñas 
Blancas están mal ubicados, a pesar de que en el segundo mapa de von Frantzius ya ocupaban la posición correcta.

24. El citado muelle corresponde al embarcadero que había en la ribera derecha del río, muy cerca de la desembocadura del río San Rafael, afluente suyo, y que dio origen el actual poblado de Muelle. En ese sitio hay un hito histórico alusivo a la Ruta de los Héroes (Figura 7C), pues en diciembre de 1856 de ahí partieron las tropas que combatieron al ejército filibustero en el río San Juan.

25. En cuanto a los islotes, llamados islas hoy, no coinciden en cantidad ni en nomenclatura con los de las hojas cartográficas respectivas (121 Cutris, 120 Infiernito, 062 Tres Amigos y 070 Aguas Zarcas). Los únicos nombres que subsisten son Canacas, Santa Rita y Tres Amigos, pero su ubicación hace dudar de que a Guzmán los lugareños le dieran bien los datos, o que él los registrara bien. Por ejemplo, entre Canacas y Santa Rita hay dos islas, llamadas Los Castaños y La Mona, una de las cuales quizás era la Rosalía de entonces; además, después de Tres Amigos hay cinco grupos de islotes (El Cubano, Cabros, Los Pobres, Sábalo y los del Cura) y no cuatro, cuyos nombres no corresponden del todo a los actuales. En síntesis, Guzmán mencionó los nombres de ocho y no de diez islotes, la secuencia de ellos es diferente, y apenas tres nombres son coincidentes con los actuales. Para agregar confusión, von Bülow menciona la isla del Socorro, a unos $15 \mathrm{~km}$ de Muelle.

26. Alude al puesto del Resguardo Fiscal ubicado ahí con fines aduanales, debido al trasiego de mercaderías desde el río San Juan hacia el San Carlos.

27. La cifra de 15 leguas $(83,6 \mathrm{~km})$ proviene del cálculo efectuado por von Bülow entre Muelle y la desembocadura del río, y esta nueva estimación corresponde a unos $90 \mathrm{~km}$, bastante cercana al dato real, que es de casi 88 km, según el experto Juan Manuel Castro.

28. La citada bifurcación, al menos aparente, se debe a la presencia de la isla Providencia en ese punto. Dicho islote pertenece hoy a Nicaragua.

29. Al parecer, hay una omisión, pues antes no cita dichas haciendas, entre las cuales posiblemente estaba la de Victoriano Fernández. En cuanto al árbol citado, esto se discutirá posteriormente.

30. Algunas de estas cifras parecieran exageradas, al igual que la de una "raíz monstruo de zarzaparrilla" que pesaba 268 libras, proveniente de San José y aportada por Ezequiel Jiménez; este último dato figura en el catálogo. Sin embargo, para el ñame podría ser factible ese peso en ciertos tipos de suelos, según el especialista Pedro Hernández. Por su parte, en el dato de la caña debe haber un error, pues corresponde a $29 \mathrm{~cm}$, algo impensable para el tallo de una planta como esa; aún si correspondiera a $11 \mathrm{~cm}$, sería un valor muy alto.

31. Es posible que se tratara de Modesto Murillo, citado en su catálogo como proveedor de cacao beneficiado.

32. En este caso no alude a la célebre y pronunciada pendiente del cauce del río La Vieja, sino más bien a las estribaciones de lo que él mismo denominara "las montañas o cordilleras de La Vieja", representadas por los volcanes Platanar y Porvenir.

33. Es obvio que la analogía con El Dorado, mítico lugar suramericano, no se refería a minas de oro, sino a las incontables riquezas naturales de San Carlos; en un pasaje de su catálogo, 
Guzmán también calificó así a Golfo Dulce y Talamanca. Al ferrocarril y al canal se aludió previamente; nótese que aquí Guzmán se refiere al río Frío, en la zona de Upala.

34. El distrito de Buenavista (a $865 \mathrm{~m}$ de altitud) se localiza levemente hacia el suroeste de Sucre, poblado que se ubica en la carretera principal (Ruta 141).

35. Se ignora el paradero de tan valioso testimonio pictórico. Nótese que menciona 172 fotografías de Guanacaste, en contraste con las 235 que citó al regresar de su viaje a esa provincia, lo cual sugiere que al final muchas se malograron.

36. En la documentación aparecen los nombres de Jesús Valverde S., Francisco Alvarado y Rafael Rodríguez Madrigal, jefes políticos de San Mateo, Esparza y Naranjo, respectivamente. En la gira a Guanacaste fungió como agente José Lino Matarrita Vega, en Nicoya.

37. Acerca de estas muestras, al palo de la vaca se aludirá pronto. La corteza del camíbar de esa zona (Copaifera aromatica) produce una resina aromática con propiedades cicatrizantes. De la madera de cuasia u hombre grande (Quassia amara) se extraen gotas amargas con propiedades digestivas y actividad insecticida. La gutapercha es una goma con propiedades parecidas al hule, con varios usos industriales, la cual se extrae del árbol de Palaquium gutta, que en el apéndice de su catálogo Guzmán consigna como Isonandra guta; él indica que no la había hallado en Costa Rica, pero no dudaba de que estuviera aquí, lo cual carece de fundamento, pues es exclusiva de varias islas del archipiélago malayo. En cuanto a la muela de mastodonte, ese dato es nuevo para el especialista Guillermo Alvarado Induni, quien indica que la primera recolección y clasificación taxonómica conocida de un vertebrado fósil en Costa Rica la aportó el naturalista Anastasio Alfaro en 1905, al referirse a unos molares de caballos fósiles recolectados en Aserrí; esto sugiere que, a pesar de su gran tamaño, esa pieza desapareció.

38. Además de la búsqueda en publicaciones taxonómicas pertinentes, como León y Poveda (2000) y Hammel (2005), debo esta información a los expertos Quírico Jiménez (árboles y algunas otras plantas), Michael Grayum (palmas), Alexander F. Rojas (helechos), Barry Hammel (plantas ornamentales) y Francois Anthony (café).

39. Debo esta aclaración a los expertos Quírico Jiménez y Michael Grayum.

40. Además de la búsqueda en publicaciones taxonómicas pertinentes, como Bussing (1987), Stiles y Skutch (1995) y Carrillo et al. (1999), debo esta información a los expertos Myrna I. López (peces), Alejandro Solórzano (serpientes), Pablo Elizondo (aves) y Eduardo Carrillo (mamíferos).

\section{Bibliografía}

Bussing, W.A. (1987). Peces de las aguas continentales de Costa Rica. San José: Editorial de la Universidad de Costa Rica.

Carrillo, E., G. Wong y J.C. Sáenz. (1999). Mamíferos de Costa Rica. Heredia: Instituto Nacional de Biodiversidad (INBio).

Díaz, R.E. (2005). “Las contribuciones del Dr. Don David Joaquín Guzmán al desarrollo científico costarricense (1890-1896)". Memoria: Primer Encuentro de 
Historia de El Salvador. 22-25 de julio de 2003. Universidad de El Salvador, San Salvador. CONCULTURA.

Guzmán, D.J. (1892a). Catálogo general de los objetos que la República de Costa Rica envía a la Exposición Universal de Chicago. San José: Tipografía Nacional.

Guzmán, D.J. (1892b). Estudio sobre el cultivo de algunas plantas y árboles industriales susceptibles de explotarse en la República de Costa Rica. San José: Tipografía Nacional.

Hammel, B. (2005). Plantas ornamentales nativas de Costa Rica. Heredia: Instituto Nacional de Biodiversidad (INBio), $3 .^{\circ}$ ed.

Hilje, L. (2009a, 20 de abril). "Bruno von Natzmer, delincuente y filibustero". Diario digital ElPaís.cr.

Hilje, L. (2009b, 25 de mayo). En busca de Koschny. Diario digital ElPaís.cr.

Hilje, L. (2013). Trópico agreste; la huella de los naturalistas alemanes en la Costa Rica del siglo XIX. Cartago: Editorial Tecnológica de Costa Rica.

Humboldt, A. (2005). Del Orinoco al Amazonas; viaje a las regiones equinocciales del Nuevo Continente. Barcelona: Editorial Planeta.

León, J. y L.J. Poveda. (2000). Los nombres comunes de las plantas en Costa Rica. San José: Editorial Guayacán.

Montúfar, L. (2000). Walker en Centroamérica. Alajuela: Museo Histórico Cultural Juan Santamaría.

Ossenbach, C., F. Pupulin y R. Jenny. (2013). Orchids in the life and work of Auguste R. Endrés. Vol. 1. The texts. Verlag des Naturhistorischen Museums, Viena.

Pittier, H. (1908). Ensayo sobre las plantas usuales de Costa Rica. Washington D.C.: H.L. \& J.B. McQueen.

Quesada, F. (1958). "Monografía de San Carlos". Alajuela: Edición particular.

Stiles, F.G. y A.F. Skutch. (1995). Guía de aves de Costa Rica. Heredia: Instituto Nacional de Biodiversidad (INBio).

Tosi, J.A. (1969). Mapa ecológico de Costa Rica, basado en la clasificación de zonas de vida del mundo de L.R. Holdridge. San José: Centro Científico Tropical.

Von Bülow, A. (1854). Informe sobre el camino y la navegación del río "San Carlos". San José: Imprenta de la Paz.

Von Frantzius, A. (1862). "La ribera derecha del río San Juan; hasta ahora una parte casi completamente desconocida de Costa Rica". Anales del Instituto Físico Geográfico. Tomo V. p. 105-119. 


\section{Agradecimientos}

Dedico este artículo a la memoria de Alberto y Guillermo Quesada Rodríguez, de su padre Lupicio Quesada Quesada, y de mi tío Ricardo Quirós Rodríguez, todos corajudos hombres que labraron sus vidas en las agrestes montañas sancarleñas.

Agradezco la información biológica aportada por Quírico Jiménez Madrigal, Michael Grayum, Alexander F. Rojas Alvarado, Barry Hammel, Francois Anthony, Carlos Ossenbach, Pedro Hernández Fernández, Myrna I. López de Bussing, Alejandro Solórzano López, Pablo Elizondo Camacho y Eduardo Carrillo Jiménez, así como la información geológica brindada por Guillermo Alvarado Induni. Además, a Edgardo Vargas Jarquín y a Fabián Vargas Hernández (Instituto Tecnológico de Costa Rica, Sede de Santa Clara), el apoyo para un viaje hasta la desembocadura del río San Carlos.

Algunos valiosos datos históricos fueron suministrados por Jorge Rolando Molina González, Carlomagno Rojas Rodríguez, Ronald Díaz Bolaños, Brunilda Hilje Quirós, Emilio Obando Cairol, Gisela Kopper Arguedas, Albán Jesús Cambronero Acosta, Juan Manuel Castro Alfaro, Jorge León Sáenz y Miguel Ángel Quesada Pacheco.

Además, el Museo Nacional de Antropología Dr. David J. Guzmán, de El Salvador, por medio de Sebastián Vaquerano López (Embajador de El Salvador en Costa Rica) me facilitó la fotografía del Dr. Guzmán; Silvia Meléndez Dobles, el mapa de Friederichsen; Cosme Mejía Koschny, la foto de la casa de su ancestro; también, Fabio Jiménez Salas (Archivo Nacional) reprodujo la foto del pabellón de Costa Rica en Chicago, y Felipe Abarca Fedullo retocó varias imágenes. Asimismo, Laura Rodríguez Amador y Jaime García González consiguieron el informe de von Bülow sobre el camino de San Carlos. Finalmente, Elsa Pérez Villalón transcribió el documento original de Guzmán, y Theresa White revisó el resumen en inglés. 